Finance and Economics Discussion Series Divisions of Research \& Statistics and Monetary Affairs Federal Reserve Board, Washington, D.C.

\title{
The Effect of Housing Government-Sponsored Enterprises on Mortgage Rates
}

Wayne Passmore, Shane M. Sherlund, and Gillian Burgess

2005-06

NOTE: Staff working papers in the Finance and Economics Discussion Series (FEDS) are preliminary materials circulated to stimulate discussion and critical comment. The analysis and conclusions set forth are those of the authors and do not indicate concurrence by other members of the research staff or the Board of Governors. References in publications to the Finance and Economics Discussion Series (other than acknowledgement) should be cleared with the author(s) to protect the tentative character of these papers. 


\title{
The Effect of Housing Government-Sponsored Enterprises on Mortgage Rates
}

\author{
Wayne Passmore, Shane M. Sherlund, and Gillian Burgess \\ Federal Reserve Board ${ }^{1}$
}

Forthcoming in Real Estate Economics ${ }^{2}$

Please do not cite or circulate without permission of the authors.

\begin{abstract}
We derive a theoretical model of how jumbo and conforming mortgage rates are determined and how the jumbo-conforming spread might arise. We show that mortgage rates reflect the cost of funding mortgages and that this cost of funding can drive a wedge between jumbo and conforming rates (the jumbo-conforming spread). Further, we show how the jumbo-conforming spread widens when mortgage demand is high or core deposits are not sufficient to fund mortgage demand, and tighten as the mortgage market becomes more liquid and realizes economies of scale. Using MIRS data for April 1997 through May 2003, we estimate that the GSE funding advantage accounts for about seven basis points of the 15-18 basis point jumbo-conforming spread.
\end{abstract}

\footnotetext{
${ }^{1}$ The opinions, analysis, and conclusions of this paper are solely the authors' and do not necessarily reflect those of the Board of Governors of the Federal Reserve System. Ms. Burgess is now a student at New York University's School of Law. We wish to thank Mary DiCarlantonio, Paul Landefeld, and Cathy Gessert for their excellent research assistance. We also wish to thank three anonymous referees and our many colleagues at the Federal Reserve Board and at the Federal Reserve Banks for their useful and constructive comments, including Glenn Canner, William Cleveland, Darrel Cohen, Chris Downing, Karen Dynan, Ed Ettin, Kieran Fallon, Ron Feldman, Scott Frame, Steve Friedman, Mike Gibson, Alan Greenspan, Diana Hancock, Richard Insalaco, Kathleen Johnson, Myron Kwast, Andreas Lehnert, Brian Madigan, Norman Morin, Steve Oliner, Pat Parkinson, Richard Peach, Karen Pence, Bob Pribble, Brian Sack, David Stockton, Pat White, and David Wilcox. We would also like to thank the staffs at the Congressional Budget Office, the Council of Economic Advisors, the Department of the Treasury, and the Office of Management and Budget for their comments, including David Torregrosa and Mario Ugoletti. We also thank William Greene for helpful comments.

${ }^{2}$ Real Estate Economics is the Journal of the American Real Estate and Urban Economics Association and is located at the Leeds School of Business, University of Colorado-Boulder, Boulder, CO, 80309-0419 (email: REE@colorado.edu). Portions of this paper were included in an earlier version of "The GSE Implicit Subsidy and the Value of Government Ambiguity," Federal Reserve Finance and Economics Discussion Series, No. 2003-64, December 2003.
} 


\section{Introduction}

Congress created two government-sponsored enterprises, the Federal National Mortgage Association (Fannie Mae) and the Federal Home Loan Mortgage Corporation (Freddie Mac) with the goal of providing banks, thrifts, and other mortgage originators with a liquid secondary market that would provide an alternative to funding mortgages with deposits. A secondary mortgage market allows mortgage originators to respond more quickly to fluctuating mortgage demand and to lower mortgage rates for some homeowners when mortgage demand is high.

When Congress created the GSE charters, they provided the GSEs with a variety of special benefits. ${ }^{3}$ Initially, many viewed these benefits as a way to enhance the GSEs' efforts in establishing a secondary mortgage market. However, with the secondary mortgage market well established and with many other well-functioning purely private secondary markets, the justification for the GSEs' benefits has shifted to the GSEs' success in lowering mortgage rates and in encouraging affordable housing.

The GSEs benefit from the government-sponsored status because purchasers of their debt assume that the government will not allow the GSEs to fail, even though the government has made no explicit promise to bail out the GSEs should problems arise. This ambiguous government relationship creates an implicit government subsidy to the GSEs that is worth billions of dollars (CBO, 2001). In this paper, we estimate the proportion of this implicit subsidy that GSEs transmit to homeowners via lower mortgage rates.

Like many previous studies, this paper focuses on the difference in mortgage rates observed on mortgages that exceed the size limit imposed on GSE mortgage purchases (jumbo mortgages) and mortgages below this size limit. Many previous studies assume that the spread between jumbo and conforming mortgage rates is a measure of the effect of GSEs. This assumption ignores segmentation of the jumbo securitization market as well as the effects of bank funding capacity, banks' investment alternatives, and fluctuating mortgage demand on mortgage rates. When one considers a hypothetical world without GSEs, researchers need to consider both the possibility that conforming rates will rise and that jumbo rates will fall. Currently, the jumbo mortgage securitization

\footnotetext{
${ }^{3}$ A review of these benefits can be found in Mankiw (2003) and CBO (2001).
} 
market is artificially segmented from the conforming market because of the conforming loan limit and therefore cannot realize the economies of scale or scope of the conforming MBS market. ${ }^{4}$ Thus, the jumbo-conforming spread is an upper bound on the extent to which mortgage rates might rise if GSEs lost their special status. Our research suggests that the typical jumbo-conforming spread is between 15 and 18 basis points and that the GSE funding advantage likely accounts for about seven basis points of this difference.

\section{The Effect of the GSE Implicit Subsidy on Mortgage Rates}

Given the many intermediaries between the source of the subsidy (investors who view the GSEs as backed by the government) and the target of the subsidy (homeowners), the GSEs' presence does not necessarily change mortgage rates very much. As argued by Goodman and Passmore (1992) and Hermalin and Jaffee (1996), much of the subsidy may not be transmitted to homeowners. This is because the conforming mortgage market has many of the conditions required for imperfect competition among competitors - two competitors (Fannie Mae and Freddie Mac) with roughly equal market share, homogeneity of product, high entry and exit barriers, and each with almost infinite production capacity. ${ }^{5}$ In addition, Fannie and Freddie - like all insurers of credit risk - face an adverse selection problem, which requires that they include a "lemons premium" in the purchase price they offer for mortgages.

Theoretically, the GSEs' efforts to avoid adverse selection could then completely absorb the subsidy (Passmore and Sparks, 1996). This outcome has become more likely with the advent of automated underwriting because mortgage originators can determine, with little cost, whether GSEs will purchase a mortgage (Passmore and Sparks, 2000). Finally, because the mortgage originators who are depository institutions always decide first which mortgages to keep and which to sell (a "first mover advantage"), the GSEs - even if they desire to pass on a subsidy to homeowners - might not be able to use the mortgage banking system to actually transmit the subsidy because of the banks' relative advantage

\footnotetext{
${ }^{4}$ Passmore, Sparks, and Ingpen (2002) investigate the effect of this segmentation. Other factors can also create differences between conforming and jumbo mortgage rates - differences that are unrelated to the GSEs. For example, Ambrose, Buttimer, and Thibodeau (2001) find that the variance in house prices is Ushaped, possibly because of risk-based pricing, and therefore contributes to the jumbo-conforming spread.

${ }^{5}$ Neither study, however, is able to establish that Fannie and Freddie actually collude.
} 
in bargaining over pricing and underwriting standards (Heuson, Passmore, and Sparks, 2001).

Congress created the GSEs with the goal of providing banks with a source of mortgage funding other than deposits. The GSEs enable banks to sell mortgages into a secondary market during times when high mortgage demand and limits on bank capacity for holding additional assets constrain mortgage funding. Putting aside the more complicated arguments about the relative bargaining power of GSEs outlined above, a secondary mortgage market - whether GSEs are involved or not - enables mortgage originators to respond more quickly to fluctuating mortgage demand and lowers mortgage rates for some homeowners when mortgage demand is high. ${ }^{6}$ GSEs may or may not provide this "extra capacity" to the banking system at a lower cost than private securitizers.

Mortgage rate studies based on data from the late 1980s and early 1990s generally conclude that mortgage rates for conforming mortgages were about 20 to 40 basis points less than mortgage rates for jumbo mortgages (Hendershott and Shilling, 1989; Cotterman and Pearce, 1996). Passmore, Sparks, and Ingpen (2002) show that better screening of the data combined with the use of more up-to-date information lowers the estimate of the typical spread between jumbo and conforming mortgage rates to about 20 basis points. McKenzie (2002) provides an extensive survey of this literature and estimates the spread to be 22 basis points over a long horizon (1986-2000) and 19 basis points during a more recent period (1996-2000). Torregrosa (2001) found similar results for this latter period (1995-2000), with estimates ranging from 18 to 25 basis points depending upon the estimation technique and screening of the data. ${ }^{7}$

Ambrose, LaCour-Little, and Sanders (2002) conduct a unique study that, unlike many other studies of the effect of GSEs on mortgage rates, does not rely on the Federal Housing Finance Board's Mortgage Interest Rate Survey (MIRS). Using data from an

\footnotetext{
${ }^{6}$ Ambrose and Thibodeau (2004) find that the GSEs' affordable housing goals increased the supply of mortgage credit to underserved markets, particularly during the refinance wave of 1998.

${ }^{7}$ The GSEs also produce studies arguing that they lower mortgage rate volatility as well as lower mortgage rates (Naranjo and Toevs, 2002). However, simultaneous movements of mortgage rates, mortgage spreads, volatility, and GSE purchase activity likely confound these volatility impact estimates. As a result, the estimates likely reflect simultaneity bias. Unfortunately, there has been little independent research in this area. In addition, these studies rarely address how a GSE behaves differently than other non-GSE private purchasers in secondary markets and thus why government sponsorship is needed.
} 
unidentified large national lender, they have much better measures of borrower credit quality and of a mortgage's conforming loan status than studies based on the MIRS data. After taking into account borrower characteristics, house price volatility, and endogeneity and sample selection issues, they find that jumbo mortgage rates are about 27 basis points higher than conforming mortgages. Further, they decompose this spread into the conforming-nonconforming ${ }^{8}$ spread ( 9 basis points), the jumbo-nonconforming spread (15 basis points), and house price volatility ( 3 basis points). They conclude that the GSEs account for between 9 and 24 basis points of the jumbo-conforming spread, depending on whether one perceives the jumbo-conforming spread or the conformingnonconforming spread as being a result of GSE activities.

\section{GSEs, the Banking Industry, and the Jumbo-Conforming Spread}

\section{The Demand for Mortgages}

Using a simple model of mortgage demand, we illustrate that the jumboconforming spread changes with fluctuations in mortgage demand, the attractiveness of banks' alternative non-mortgage investments, and with the banking industry's capacity to collect core deposits. We assume that households maximize the utility they receive from their allocation of wealth. We use a quadratic utility function, so that household utility increases as housing wealth increases until wealth reaches the bliss point, $W^{*}$. Any increase in housing wealth beyond $W^{*}$ decreases household utility. Given a certain value of housing wealth, $w$, household utility is then

$$
U(w)=-\frac{1}{2}\left(w-W^{*}\right)^{2} .
$$

At the time a mortgage payment is due, the household must decide whether to pay or to default on the mortgage. In our one-period model, we assume that the household makes a down payment, $p$, which is a constant percentage of the total mortgage amount, $M$. Then the household must repay the entire mortgage balance with interest, $\left(1+r_{M}\right) M$, or default on the mortgage. The house is then sold at its realized liquidation value.

\footnotetext{
${ }^{8}$ A nonconforming loan satisfies the GSEs' loan size requirement, but fails to meet some other criteria (for example, LTV ratio and credit score requirements).
} 
The liquidation value of the house (as a percentage of the purchase price), $l$, has a distribution that is known ex ante to both the borrower and the bank extending the mortgage. The household decides whether to repay the mortgage or default after observing the realized liquidation value. If the amount of the mortgage plus interest, $\left(1+r_{M}\right) M$, less the default cost, $c_{d e f} M$, is greater than the liquidation value of the house, $l M$, the household defaults. Otherwise, the household repays. The default cost encompasses the stigma that the household incurs from defaulting on such a large debt. This stigma mainly takes the form of a lower credit rating.

Given the distribution of house liquidation values, $f(l)$, repayments and defaults have known probabilities. The household repays with probability $q$ and therefore defaults with probability $(1-q)$, where

$$
q=\int_{1+r_{M}-c_{d e}}^{\infty} f(l) d l .
$$

Housing wealth depends on whether the household repays the mortgage. If the household does repay, housing wealth is the difference between the realized liquidation value and the total amount paid on the house:

$$
w^{R}=\left(\frac{l-p-r_{t} p}{1-p}-\left(1+r_{M}\right)\right) M,
$$

where $r_{t}$ is the risk-free Treasury rate. Here, the first expression is the gross proceed from selling the house less the down payment and the opportunity cost of the down payment. Housing wealth under default is the amount lost from the down payment plus the cost of default:

$$
w^{D}=\left(\frac{-p-r_{t} p}{1-p}-c_{d e f}\right) M .
$$

Expected household utility is therefore

$$
E[U(w)]=q U\left(w^{R}\right)+(1-q) U\left(w^{D}\right) .
$$

The household maximizes expected utility with respect to mortgage size, resulting in the first-order condition: 


$$
\begin{aligned}
\frac{d E[U(w)]}{d M} & =q\left[\left(\frac{E[l]-p-r_{t} p}{1-p}-\left(1+r_{M}\right)\right) M-W^{*}\right]\left(\frac{E[l]-p-r_{t} p}{1-p}-\left(1+r_{M}\right)\right) \\
& +(1-q)\left[\left(\frac{-p-r_{t} p}{1-p}-c_{d e f}\right) M-W^{*}\right]\left(\frac{-p-r_{t} p}{1-p}-c_{d e f}\right)=0 .
\end{aligned}
$$

This implies that the household's optimal mortgage size is

$$
M^{*}=\frac{q\left(\frac{E[l]-p-r_{t} p}{1-p}-\left(1+r_{M}\right)\right)+(1-q)\left(\frac{-p-r_{t} p}{1-p}-c_{d e f}\right)}{q\left(\frac{E[l]-p-r_{t} p}{1-p}-\left(1+r_{M}\right)\right)^{2}+(1-q)\left(\frac{-p-r_{t} p}{1-p}-c_{d e f}\right)^{2}} W^{*} .
$$

Under this formulation, mortgage demand depends on optimal housing wealth $\left(W^{*}\right)$, the risk-free interest rate $\left(r_{t}\right)$, the down payment ratio $(p)$, the cost of default $\left(c_{d e f}\right)$, expected house prices $(E[l])$, the probability of default $(q)$, and the mortgage rate $\left(r_{M}\right)$.

\section{The Bank Cost Function and the Supply of Mortgages}

Turning now to the supply side of the market, we differentiate between two types of financial institutions that issue mortgages: Commercial banks and mortgage bankers. Commercial banks typically fund mortgages using deposits (and are therefore required to build the "bricks and mortar" associated with raising core deposits). Primary mortgage

originators, however, sell their mortgages shortly after origination. Both entities can sell mortgages they originate in the secondary mortgage market, but each entity has very different cost structures, affecting the mortgage supply function.

To collect a given amount of deposits, banks must raise capital, $K$, to invest in bricks and mortar. Banks pay the market rate on equity, $r_{e}$, for this capital. Deposits cost banks $c_{d e p}<r_{e}$. Bricks and mortar place a capacity constraint, $\bar{D}$, on the amount of deposits, $D$, and therefore the amount of mortgages that banks can hold. If mortgage demand exceeds this capacity constraint, banks must sell the excess mortgages.

Banking profits will depend on whether or not deposit capacity is adequate. In the low demand case, banks can retain all the mortgages they originate. They invest their excess deposits in an alternative investment that produces a lower rate of return than mortgages, $r_{a l t}$. The return on mortgages depends on whether households repay or default. In repayment, banks receive the value of the mortgage plus interest. However, 
in default, banks receive the liquidated value of the house. The expected return on mortgages is then

$$
r_{m}=q\left(1+r_{M}\right) M+(1-q) E[l] .
$$

The expected profits in the low demand case are

$$
\pi_{L}=r_{m} M_{L}+r_{a l t}\left(D-M_{L}\right)-\frac{c_{o}^{L}}{2} M_{L}^{2}-r_{e} K-c_{d e p} D,
$$

where $M_{L}<D \leq \bar{D}$ and $c_{o}{ }^{L}$ is the cost of origination. ${ }^{9}$

Banks maximize expected profits with respect to the dollar volume of mortgages made. In the low demand case, this leads to the first-order condition:

$$
\frac{d \pi_{L}}{d M_{L}}=r_{m}-r_{a l t}-c_{o}^{L} M_{L}=0 .
$$

The marginal cost function for banks in the low demand case is thus

$$
r_{m}^{L^{*}}=r_{a l t}+c_{o}^{L} M_{L}
$$

In the high demand case, banks must sell the amount of mortgages in excess of the deposit capacity. As a result, they face higher origination costs, $c_{o}{ }^{H}$, because of overtime or using less-skilled workers. Expected profits in the high demand case are

$$
\pi_{H}^{J}=r_{m} \bar{D}+\left(r_{m}-r_{a l t}-c_{p}\right)\left(M_{H}-\bar{D}\right)-\frac{c_{o}^{L}}{2} \bar{D}^{2}-\frac{c_{o}^{H}}{2}\left(M_{H}-\bar{D}\right)^{2}-r_{e} K-c_{d e p} \bar{D}
$$

for jumbo loans and

$$
\pi_{H}^{C}=r_{m} \bar{D}+\left(r_{m}-r_{a l t}-c_{g s e}\right)\left(M_{H}-\bar{D}\right)-\frac{c_{o}^{L}}{2} \bar{D}^{2}-\frac{c_{o}^{H}}{2}\left(M_{H}-\bar{D}\right)^{2}-r_{e} K-c_{d e p} \bar{D}
$$

for conforming loans, where $M_{H}>\bar{D} \geq D$ and $c_{p}>c_{g s e}$ represent the securitization fees for purely private securitizers and GSEs, respectively.

Banks again maximize expected profits with respect to the total volume of mortgages made, resulting in the first-order conditions:

$$
\frac{d \pi_{H}^{J}}{d M_{H}}=r_{m}-r_{\text {alt }}-c_{p}-c_{o}^{H}\left(M_{H}-\bar{D}\right)=0
$$

\footnotetext{
${ }^{9}$ We have assumed that origination costs are quadratic in the amount of mortgages extended.
} 
and

$$
\frac{d \pi_{H}^{C}}{d M_{H}}=r_{m}-r_{\text {alt }}-c_{g s e}-c_{o}^{H}\left(M_{H}-\bar{D}\right)=0 .
$$

The marginal cost functions for the high demand case are thus

$$
r_{m}^{H, J^{*}}=r_{\text {alt }}+c_{p}+c_{o}^{H}\left(M_{H}-\bar{D}\right)
$$

for jumbo loans and

$$
r_{m}^{H, C^{*}}=r_{a l t}+c_{g s e}+c_{o}^{H}\left(M_{H}-\bar{D}\right)
$$

for conforming loans.

In the short run, the deposit capacity of banks is fixed at a multiple of the amount of capital raised,

$$
\bar{D}=\delta K
$$

In the long run, however, banks can raise more capital to increase this capacity. Banks adjust the deposit capacity so that the marginal cost of increasing capacity equals the marginal cost of securitization at the point where $M=\bar{D}$ (equate 3.10 and 3.15 , then solve for $M=\bar{D})$. The optimal capacity is then

$$
\bar{D}=\frac{c_{g s e}}{c_{o}^{L}} .
$$

\section{The Mortgage Banker Cost Function and the Supply of Mortgages}

Mortgage bankers obtain private sources of short-term funding, paying a rate of return repo, to finance mortgages for the short period of time between origination and securitization. Mortgage bankers require only a small amount of capital, $K^{M B}$, for which they must pay an equity rate, $r_{e}{ }^{M B}$. For mortgages that they originate, mortgage bankers incur a cost of origination, $c_{o}{ }^{M B}$.

Mortgage banking expected profits are

$$
\pi_{M B}^{J}=\left(r_{m}-c_{p}\right) M_{M B}-r_{e}^{M B} K_{M B}-\frac{c_{o}^{M B}}{2} M_{M B}^{2}-\operatorname{repo} \cdot M_{M B}
$$

for jumbo loans and

$$
\pi_{M B}^{C}=\left(r_{m}-c_{g s e}\right) M_{M B}-r_{e}^{M B} K_{M B}-\frac{c_{o}^{M B}}{2} M_{M B}^{2}-g s e \cdot M_{M B}
$$


for conforming loans. The first-order conditions are:

$$
\frac{d \pi_{M B}^{J}}{d M_{M B}}=r_{m}-c_{p}-c_{o}^{M B} M_{M B}-\text { repo }=0
$$

and

$$
\frac{d \pi_{M B}^{C}}{d M_{M B}}=r_{m}-c_{g s e}-c_{o}^{M B} M_{M B}-g s e=0 .
$$

The marginal cost functions are then

$$
r_{m}^{M B, J^{*}}=c_{p}+c_{o}^{M B} M_{M B}+\text { repo }
$$

for jumbo loans and

$$
r_{m}^{M B, C^{*}}=c_{g s e}+c_{o}^{M B} M_{M B}+\text { gse } .
$$

for conforming loans.

Exhibit 1 depicts these cost functions (equations 3.11, 3.16, 3.17, 3.24, and 3.25). The upper panel shows how mortgage rates will vary in the jumbo and conforming markets as a function of the level of mortgages. The upper-left quadrant is the jumbo market; the lower-right quadrant is the conforming market; and the upper-right quadrant and the lower panel (a blown-up version of the upper-right quadrant) map conforming mortgage rates to jumbo mortgage rates as an implicit function of the level of mortgages. The vertical deviation from the $45^{\circ}$ line in these latter plots represents the jumboconforming spread. In each graph, the dashed-dotted lines represent the under-capacity portion of commercial banks' supply curve while the dotted lines show the over-capacity portion. The dashed lines depict the mortgage banker's supply curve. Consumers, of course, will choose the lower cost of these two alternatives (commercial banks versus mortgage bankers); hence, we denote the industry supply curve in bold. Consumers may also have, on aggregate, varying degrees of housing demand. Thus, we depict three levels for mortgage demand - low, middle, and high - which, in our model, could result from low, medium, and high levels of $W^{*}$, respectively. These demand curves are the dashed-gray lines in the exhibit.

As shown in the exhibit, jumbo and conforming mortgage rates are identical when housing demand is low (the equilibrium depicted by box $\mathrm{A}$ in the upper panel). This is because banks have sufficient resources to fund the aggregate level of mortgages, 
therefore bypassing the need to securitize mortgages in the secondary market. ${ }^{10}$ In this case, all mortgages - jumbo and conforming - have the same rate and there is no jumboconforming spread. However, once commercial banks surpass their capacity, the secondary market plays a vital role in the determination of jumbo and conforming rates. In the conforming market, banks can sell excess mortgages to the GSEs. However, in the jumbo market, banks must sell to private conduits that have higher costs than the GSEs. This results in the jumbo-conforming spread because GSE securitization is less costly to banks (the box B equilibrium). Lastly, when demand is high (box C's equilibrium), mortgage bankers deliver the lowest cost mortgages to consumers. Once again, conforming loans may be sold to the lower-cost GSEs, but jumbo loans must be sold to purely private securitizers. This leads to a widening jumbo-conforming spread.

\section{Measuring How GSEs Affect Mortgage Rates}

Like Ambrose et al. (2002), we believe that other factors besides the GSEs influence the difference between jumbo and conforming mortgage rates. Our model highlights that the jumbo-conforming spread will vary across regions and across time for reasons unrelated to the GSEs' activities. As a result, the jumbo-conforming spread is a poor measure of the GSEs' influence on mortgage rates. As illustrated in the theoretical model above, the jumbo-conforming spread fluctuates with mortgage demand (it widens when demand is high), with banks' funding capacity (it widens when core deposits are scarce), and with the state of jumbo market securitization (it narrows as this market becomes more liquid and realizes economies of scale). Thus, the GSEs' implicit subsidy is only one element of the jumbo-conforming spread.

To see this more clearly, consider the pricing of mortgages from our theoretical framework. In the conforming market, mortgage rates are set according to

$$
r_{M}^{C}=\text { GSE Funding Cost }+\gamma_{2} \text { Risk Factors }+\gamma_{3} \text { Supply \& Demand }
$$

GSE profit maximization suggests that GSE Funding Cost is $c_{g s e}+(1-w)\left(c_{p}-c_{g s e}\right)$, where $w$ is the pass-through rate and $(1-w)\left(c_{p}-c_{g s e}\right)$ is the markup over $c_{\text {gse }}$. The GSEs

\footnotetext{
${ }^{10}$ Interestingly, we find evidence that the proportion of newly-originated conventional conforming mortgages sold to the GSEs increases with mortgage demand and thus depository institutions tend to keep a larger proportion of mortgages when demand is low.
} 
set $w$ in response to potential competition from non-GSE funders of mortgages. A passthrough rate close to zero indicates that mortgage rates are set from $c_{g s e}$, whereas passthrough rate close to one suggests that mortgage rates are set from $c_{p}$. Thus,

$$
r_{M}^{C}=w c_{g s e}+(1-w) c_{p}+\gamma_{2} \text { Risk Factors }+\gamma_{3} \text { Supply \& Demand } .
$$

Notice that the pass-through rate is the coefficient on $c_{g s e}$, not $c_{p}$. In the jumbo market, mortgage rates are set so that

$$
r_{M}^{J}=\text { NonGSE Funding Cost }+\phi_{2} \text { Risk Factors }+\phi_{3} \text { Supply \& Demand } .
$$

Here, NonGSE Funding Cost is equal to $c_{p}$ so that

$$
r_{M}^{J}=c_{p}+\phi_{2} \text { Risk Factors }+\phi_{3} \text { Supply \& Demand } .
$$

In these equations, mortgage rates depend on the source of funding, risk factors, supply and demand factors, and, in the conforming market, the pass-through rate. Note that we allow the pricing of risk, supply, and demand factors to differ across market segments. We can now write the jumbo-conforming spread as

$$
r_{M}^{J}-r_{M}^{C}=w\left(c_{p}-c_{g s e}\right)+\beta_{2} \text { Risk Factors }+\beta_{3} \text { Supply \& Demand } .
$$

This last equation relates the jumbo-conforming spread to differences in funding costs (through the pass-through), risk factors, and supply and demand factors across the jumbo and conforming markets.

We therefore modify the traditional regression approach to control for these factors in estimating the difference between conforming and jumbo mortgage rates. Our approach for estimating the effect of the GSEs on mortgage rates involves two sequential regressions. ${ }^{11}$ The first step captures, in a very general fashion, the variation in mortgage rates over time and across states. ${ }^{12}$ The second step captures the effects of funding costs and risk premiums on the jumbo-conforming spread, which we describe later.

\footnotetext{
${ }^{11}$ We conduct our analysis in two steps because we would not otherwise identify the effects of variables that are constant for a given state-month combination because of the multi-level, nature of our data.

${ }^{12}$ Almost all researchers in this field have used this type of regression. Raines (2004) has argued that mortgage rates quoted in the newspaper are a more reasonable source of mortgage rate data. However, these rates are "list prices," not transaction prices, and using them is equivalent to assuming that very few homebuyers shop around for the lowest mortgage rate.
} 


\section{The Jumbo-Conforming Spread}

We use the individual mortgage loan data provided by the Mortgage Interest Rate Survey (MIRS) conducted by the Federal Housing Finance Board. In our data, there are over one million closed loans from April 1997 through May 2003 (descriptive statistics are in the upper portion of exhibit 2). ${ }^{13}$ Because many of the factors affecting mortgage rates and the jumbo-conforming spread vary by state and time, we run regressions describing mortgage rates of the individual loan data grouped by state and month of origination. In particular, we run separate, monthly regressions describing mortgage rates in four states - California, New Jersey, Maryland, and Virginia - as well as for the remaining states grouped together. We consider these four states separately because they have the most developed jumbo loan markets, a relatively high number of jumbo loans each month, the most jumbo loans over the period of estimation, and no months that report zero jumbo loans. ${ }^{14}$ Controlling for state variation in mortgage rates is particularly important because states have unique laws regarding mortgage origination and foreclosure laws, which affect the cost of mortgage credit. In addition, the development of the jumbo mortgage market within states varies substantially because some states have very high home prices and therefore many homebuyers needing jumbo mortgages, whereas other states have relatively low home prices and quite limited jumbo markets.

Similar to many previous studies (Henderschott and Shilling, 1989, to Ambrose and Buttimer, 2004), we regress the mortgage rate of the loan $(R M)$ on a variety of loan characteristics. The loan-to-value ( $L T V)$ information adjusts the mortgage rate for credit risk. ${ }^{15}$ Smaller loans $(S M A L L)$ are generally more expensive to originate than larger loans and, for marketing reasons, loans for new home purchases $(N E W)$ are often priced differently than those for existing homes. In addition, mortgage bankers have a different cost structure than depository institutions, so we adjust for the type of institution $(M T G C O)$ that originates the mortgage. Finally, some borrowers pay down their mortgage rates in the form of up-front fees (FEES), so we control for this mortgage loan

\footnotetext{
${ }^{13}$ We include only 30 -year fixed rate mortgages with LTVs between 20 and 97.5 percent and loan sizes between $\$ 50,000$ and twice the conforming loan limit.

${ }^{14}$ Because the MIRS is a voluntary survey, there may be some states that have a substantial jumbo loan market, but few MIRS data reporters.

${ }^{15}$ We use four classes of loan-to-value ratios: below $75 \%$ (excluded), $75-80 \%, 81-90 \%$, and above $90 \%$.
} 
characteristic as well. ${ }^{16}$ We then compare mortgage rates on conforming mortgages (eligible for purchase by the GSEs) with mortgage rates on jumbo mortgages (ineligible for purchase by the GSEs because the loan size exceeds the conforming loan limit). The equation we estimate is

$$
R M=\alpha_{0}+\alpha_{1} J+\sum_{i=1}^{3} \alpha_{2}^{i} L T V i+\alpha_{3} N E W+\alpha_{4} S M A L L+\alpha_{5} F E E S+\alpha_{6} M T G C O+\varepsilon,
$$

for every month and state. The time- and state-varying coefficient on the jumbo loan indicator variable $(J)$ represents the effect of jumbo status on the mortgage rate.

On average (across states and months), we estimate the jumbo-conforming spread to be about 16 basis points (upper portion of exhibit 2). In addition, mortgage rates are generally higher for loans with higher loan-to-value ratios, loans for smaller mortgages ${ }^{17}$, loans with up-front fees, and loans originated by mortgage companies. Although the loan-to-value ratio is the only information on credit worthiness in MIRS, our first-step regressions explain nearly 77 percent of the variation in mortgage rates. ${ }^{18}$ The lower-left panel of exhibit 2 provides a decomposition of our jumbo-conforming spread estimate across states. The estimated jumbo-conforming spread ranges from about 15 basis points (in New Jersey) to over 18 basis points (in Maryland). The standard deviations of these estimates are large, suggesting that the estimated jumbo-conforming spread varies

\footnotetext{
${ }^{16} \mathrm{We}$ control for this feature in two ways: first, we use effective mortgage rates (as provided in the MIRS), which amortize the mortgage points and combine them with the mortgage rates, and second, to control for variation that is not accounted for by the amortization process, we use an indicator variable to specify whether or not fees were paid.

${ }^{17}$ Note that there is a potential ambiguity here in identifying the jumbo-conforming spread. This is because the "small" variable does not vary independently of the jumbo indicator variable. Thus, what we call the jumbo-conforming spread is really the jumbo to moderately-sized loan spread (in the spirit of Ambrose, Buttimer, and Thibodeau (2001). However, the reason we do this is to capture fixed costs associated with making mortgage loans. Additionally, the coefficient estimate on the "small" variable is about $0.14-$ suggesting that the jumbo to small-sized loan spread is only about 2 basis points. Removal of the "small" variable leads to a lower jumbo-conforming spread estimate of about 12 basis points.

${ }^{18}$ Note that our "low" estimate of the jumbo-conforming spread is not necessarily due to the lack of information on credit worthiness (outside loan-to-value ratios) in MIRS, as other studies have used MIRS and obtained larger estimates of the jumbo-conforming spread. Instead, we attribute our lower estimate to the later sample (April 1997 through May 2003), which is consistent with trends in the established literature (see, for instance, McKenzie (2002)), and our control for state- and time-specific effects (state-by-state, month-by-month regressions) such as differences in origination and foreclosure laws.
} 
substantially over time. ${ }^{19}$ The time patterns of the jumbo-conforming spread for the California and New Jersey markets are presented in the lower-right panel.

\section{Our Analysis of the Jumbo-Conforming Spread}

To isolate the effect of the GSE subsidy on mortgage rates, we control for a variety of factors that influence the jumbo-conforming spread, as estimated by the coefficients on the jumbo indicator variable in the first-step regressions. As we have shown, mortgage rates have several major components: The cost of funding the mortgage (the risk-free cost of funds, $R T$, and the GSE funding advantage, $G A$ ) and the spreads needed to compensate for the credit $(C R)$, prepayment $(P R)$, and maturitymismatch $(M R)$ risks of the mortgage. ${ }^{20,21}$ Each of these factors could be priced differently for jumbo mortgages versus conforming mortgages (thereby affecting the jumbo-conforming spread), especially given the truncated and idiosyncratic nature of the secondary market for jumbo mortgages. In line with our model, we also include measures for aggregate demand (DEM), the long-term interest rate (LTRT), and market capacity $(C A P)$. Finally, we include a time trend to capture any developmental differences $(D E V)$ between the jumbo and conforming markets and indicator variables for state (STATE) and quarter $(Q T R)$ of origination to capture state and seasonal effects. The second-step regression we ultimately estimate takes the form

$$
\begin{aligned}
\alpha_{1}= & \beta_{0}+\beta_{1} G A+\beta_{2} R T+\beta_{3} C R+\beta_{4} P R+\beta_{5} M R+\beta_{6} D E M+\beta_{7} L T R T \\
& +\beta_{8} C A P+\beta_{9} D E V+\sum_{s=1}^{4} \beta_{10}^{s} S T A T E_{s}+\sum_{j=1}^{3} \beta_{11}^{j} Q T R_{j}+\eta .
\end{aligned}
$$

We proxy for the credit risk spreads associated with conforming mortgages using the spread between a rate offered on a home equity line of credit (where the combined loan-to-value of the first and second mortgages cannot exceed 80 percent) and a

\footnotetext{
${ }^{19}$ This should not be confused with statistical significance. The jumbo-conforming spread estimates are generally highly significant. The point is that the jumbo-conforming spread varies substantially over time. ${ }^{20}$ Maturity-mismatch risk is the risk that an institution's liability structure could become out of line with the duration of its assets and that it might be costly to adjust the liabilities to match the asset duration appropriately.

${ }^{21}$ Interest rate risk is sometimes identified as maturity-mismatch risk and sometimes identified as the combination of this risk and prepayment risk. We will use the more precise language here.
} 
conforming, one-year adjustable rate mortgage. ${ }^{22}$ Because home equity loans are backed by second liens and mortgages are backed by first liens, movements in this spread should partly reflect the small changes in credit risks associated with homeowner delinquency or default for very safe mortgages.

We compare the daily yield on the current coupon Fannie Mae mortgage-backed security to a duration-matched yield on AAA/AA financial corporate debt to measure prepayment risk. $^{23}$ The maturity-mismatch risk spread is measured as the difference between the duration-matched corporate yield and the average yield on financial corporate funding, as weighted by the GSEs' distribution of debt maturities. ${ }^{24}$ We use the one-year Treasury rate to proxy for the risk-free cost of funds and the ten-year Treasury rate as a measure of the opportunity costs of funding housing (for both portfolio lenders and households). Our deposit capacity variable is measured as the ratio of total deposits at banks to total household wealth, while the aggregate mortgage demand variable is measured as the ratio of total housing wealth to total household wealth.

\section{Our Method for Estimating the GSE Funding Advantage}

To calculate the GSE debt advantage, we assume that the GSEs' long-term debt advantage is the spread between observed yields on AAA/AA financial corporate debt and GSE debt, with maturities from one to ten years. ${ }^{25}$ It is not clear what corporations are best for this comparison. On one hand, Fannie Mae and Freddie Mac are currently rated AAA, partly because of their GSE status, and thus one might consider choosing AAA corporations. On the other hand, without GSE status, the GSEs would be rated below AAA unless they raised substantial capital or took other actions to offset the loss

\footnotetext{
${ }^{22}$ The rate on the home equity line of credit is from Bank Rate Monitor and the adjustable-rate mortgage rate is from Freddie Mac.

${ }^{23}$ These corporate bonds have almost no credit risk. We take the monthly averages for the variables on the right-hand side of the second-step regression. We use Bloomberg's daily calculation of the MBS current coupon and then match that duration using a daily corporate yield curve for AA/AAA financial corporations to find duration-match values. The daily yield curves are calculated using the technique of Nelson and Siegel (1987), as implemented in Bolder and Stréliski (1999).

${ }^{24}$ This is a measure of how far the GSE debt distribution is out of alignment with the current duration of mortgages.

${ }^{25}$ We stopped at ten years because there are few comparable corporate debt issues with longer maturities.
} 
of this status. ${ }^{26}$ Almost all financial corporations, however, find that a AA or A rating is sufficient; few pursue a AAA rating. In an effort not to overstate the subsidy, we use AAA/AA financial corporations for our comparison. ${ }^{27}$

For both GSE and corporate long-term debt, we take the average yield on outstanding debt grouped by maturity "buckets" (using debt with remaining maturity from 1 to 3 years, 3 to 5 years, 5 to 7 years, and 7 to 10 years) for each day and then take the weighted-average of the yields on these four buckets, weighted by the proportion of GSE debt in each "bucket." Thus, the maturities on corporate debt outstanding are adjusted to match GSE maturities. ${ }^{28}$

As shown in the upper portion of exhibit 3, we create four different indices of corporate debt spreads, where each index measures liquidity in a slightly different manner. Our first index uses all 68 firms - regardless of issue size or frequency. The second index is based on the shear size of the debt issuance. Any issue above $\$ 1$ billion is included in this index. There are 15 companies (4 foreign, 11 domestic) in this index. Here, the assumption is that the size of the debt issue is an important aspect of liquidity.

Our third index is also based on the size of the issue. We include any issue that exceeds the median size of GSE issues in any given year. In 1997, this issuance threshold was $\$ 165$ million. By 2003, it had grown to \$696 million. There are 44 companies (11 foreign, 33 domestic) in this index. U.S. investors should be familiar with these issuers and thus one might assume that these issues are liquid. The fourth index is based on the debt issuance of GE Capital. Among the financial corporations in our sample, GE Capital issued debt most frequently and in substantial quantities. As shown

\footnotetext{
${ }^{26}$ Besides the AAA ratings that are based partly on their GSE status, Fannie Mae and Freddie Mac are given "bank financial strength" ratings by Moody's that assume that GSE status is withdrawn but that there are no other changes that affect the firms (such as changes in agency yields). These ratings are not meant to be compared to Moody's other credit risk ratings. Fannie Mae and Freddie Mac's rating of A- is the second-to-best rating and represents the rating Fannie Mae and Freddie Mac would have without GSE status but with no other change in their status (such as their role in the housing system or their funding costs). Nothaft, Pearce, and Stevanovic (2002) state, "We believe the Standard and Poor's and Moody's ratings of Freddie Mac and Fannie Mae imply that the relevant comparators for estimating the long-term GSE funding advantage are securities rated AA-." Fannie Mae's financial reports also suggest that they manage their business to a AA standard (see FNMA 10-K report, December 31, 2003, page 56).

${ }^{27}$ The U.S. Department of the Treasury (1996) used a similar approach but settled on A-rated financial firms for the comparison group, arguing that this rating was common for high-quality financial firms with large portfolios of mortgages. We use Merrill Lynch's financial corporation data and rely on their classification of corporations. Roughly one-third of the companies are AAA and the remainder are AA. ${ }^{28}$ This "bucketing" technique is similar to that used in Sanders (2002).
} 
in the exhibit, the first three measures indicate an average long-term debt advantage of 38 to 44 basis points, with standard deviations between 13 and 18 basis points. The measure based on GE Capital, however, suggests an average long-term debt advantage of about 24 basis points, with a standard deviation of 14 basis points. We use each of these indices in our estimation of the GSE funding advantage.

For debt with a maturity of less than one year, we calculate the short-term advantage as the spread between yields on GSE discount notes and repurchase agreements using GSE mortgage-backed securities as collateral. We use MBS repos because Fannie and Freddie hold large amounts of this collateral in their portfolios and thus could use this market-based funding alternative. ${ }^{29}$ As shown in the lower-left panel of exhibit 3 , the short-term debt advantage averages about 13 basis points, with a standard deviation of 6 basis points.

Next, we assume that the GSEs' mortgage portfolio is effectively funded at the weighted-average yield on longer-term debt (regardless of whether longer-term debt is issued and swapped to shorter maturities, shorter-term debt is issued and swapped to longer maturities, or debt is issued without engaging in a swap) and that the remainder of GSE assets are funded using short-term debt (the GSEs supposedly issued this debt either to provide liquidity or to take advantage of short-term arbitrages using their GSE advantages). This approach assumes that the GSEs' target debt maturity is the weightedaverage maturity of their stock of debt. Rather than issue all debt at one maturity, however, they sometimes find it cheaper and less risky (because the tiering of maturities partly offsets the uncertainty about mortgage prepayments) to issue at other maturities, as well as engage in swaps. This approach also assumes that the GSEs' funding advantage is only the yield difference on debt and is not in the swap transaction (although GSE status does give the GSEs some advantages with regard to posting collateral for swaps, as found in Jaffee (2003)). Finally, this approach assumes that the weighted-average yield captures the effective cost of issuing debt adjusted for the prepayment risks associated with holding mortgages. Thus, the GSEs' total debt advantage is the average of these

\footnotetext{
${ }^{29}$ MBS repo rates could themselves embed an implicit subsidy because of the GSE collateralization. We therefore substitute the AA corporate commercial paper rate and find that our results are little changed.
} 
two spreads, weighted by the percent of debt used to fund mortgages. ${ }^{30}$ As can be seen in the lower-right panel, the GSEs issued more debt than needed to fund their mortgage holdings, typically using about 109 percent of the debt needed for funding mortgages.

\section{Regression Analysis}

As described earlier, our estimated jumbo-conforming spreads reflect many different effects besides the GSE advantage. We therefore perform a second-step regression on the 370 estimates (one estimate for each state and for each month of data) of the jumbo-conforming spread from the first-step regressions to adjust for certain factors that influence the spread. ${ }^{31}$ We include measures for the GSE funding advantage, mortgage risk characteristics, aggregate mortgage demand, mortgage market capacity, a time trend to capture development of the market, and dummies for states and quarters to capture seasonal and region-specific effects (descriptive statistics for these variables are provided in exhibit 4).

Recalling the second-step regression equation, the fraction of the GSE debt advantage transmitted to homeowners (the GSE pass-through) is estimated by the coefficient $\beta_{1}$ on the GSE funding advantage variable $(G A)$. Because we have four proxies for corporate yields (each reflecting a slightly different concept of corporate debt liquidity), we estimate our model four times, resulting in four (different) estimates of the pass-through from the GSEs' gross debt advantage to homeowners' mortgage rates. We use all four proxies to preserve each source of variation. Including each proxy in a single estimation poses interpretation problems, so we instead opt to estimate each specification separately, and then apply minimum distance estimation to calculate the mortgage rate savings to homeowners.

The upper portion of exhibit 5 contains our estimates for each regression. Note that the reported standard errors are corrected for heteroskedasticity, first-order autocorrelation, and clustering by month. Without such corrections, estimated standard

\footnotetext{
${ }^{30}$ This approach is similar to CBO (2001), which assumed that the GSEs' optimal mix was 80 percent long-term (greater than one year) and 20 percent short-term (less than one year). This approach effectively treats callable debt and some short-term debt (the portion swapped to have longer maturities) the same as longer-term "plain-vanilla" debt.

${ }^{31}$ In sensitivity analysis described later, we also use the difference between monthly average jumbo and conforming mortgage rates as a measure of the jumbo-conforming spread.
} 
errors would be 30-40 percent smaller. Also, note that the GSE funding advantage has a statistically significant positive effect on the jumbo-conforming spread in only two of the four cases, conditional on other important factors, such as credit, prepayment, and funding risks, funding costs, and regional factors. ${ }^{32}$ As expected, our regression results indicate that the jumbo-conforming spread widens when mortgage demand is high or when deposit capacity is low, and tightens as the mortgage market becomes more developed. Each source of risk (credit, prepayment, and maturity-mismatch) also appears to price differently across the jumbo and conforming markets, with the higher pricing occurring in the less-developed jumbo sector of the mortgage market (though not to a statistically significant degree).

In order to reconcile our differing estimates of the GSE pass-through, we use minimum distance estimation. The minimum distance estimator takes an implicit weighted average of the parameter estimates according to some criteria function. We minimize the quadratic form of the standardized difference between the minimum distance estimate and the four parameter estimates

$$
\min _{\hat{\beta}^{*}}\left(\hat{\beta}-\hat{\beta}^{*}\right)^{\prime} \hat{\Omega}^{-1}\left(\hat{\beta}-\hat{\beta}^{*}\right)
$$

where $\hat{\beta}$ is the vector of preliminary GSE pass-through estimates, $\hat{\beta}^{*}$ is the minimum distance estimator of the pass-through, and $\hat{\Omega}$ is the variance-covariance matrix for $\hat{\beta}$ which explicitly accounts for any correlation among the proxy variables. Because we minimize this particular criteria function, our weighting is a function of the variancecovariance terms. We report these implicit weights along with the underlying parameter estimates in exhibit 5 .

The minimum distance estimator results in a point estimate of about 16.4 percent for the GSE pass-through. The lower panel of exhibit 5 shows our estimate of the

\footnotetext{
${ }^{32}$ Due to our formulation of some of the explanatory variables, $78-85$ percent of the variation in $G A$ is explained by the other regressors. However, testing for multicollinearity is much akin to testing for micronumerosity - or small $n$ (Goldberger, 1991, ch. 23). Moreover, as Goldberger (1991, p. 252) points out, "To say that 'standard errors are inflated by multicollinearity' is to suggest that they are artificially, or spuriously, large. But in fact they are appropriately large: the coefficient estimates actually would vary a lot from sample to sample. This may be regrettable but it is not spurious." Further, the same process that leads to large standard errors also leads to large (not small) coefficient estimates, in particular the coefficient on $G A$.
} 
asymptotic distribution of the minimum distance estimator of the GSE pass-through. As shown in the exhibit, the median pass-through is about 16.4 percent and the 95-percent confidence interval runs from -1.6 percent to 34.5 percent. Also, our four preliminary pass-through estimates (dashed lines), ranging from 6.6 to 31.0 percent, span the weighted average and lie within the 95-percent confidence interval.

\section{Mortgage Rate Savings}

As shown in the upper panel of exhibit 6, we calculate that yields on Fannie and Freddie's long-term debt run about 42 basis points lower than those for our comparison group, with a standard deviation of 13 basis points. To calculate the long-term advantage, we use a weighted average of our four GSE debt advantage indexes. The weights are each index's contribution to the minimum distance estimator of the GSE pass-through, discussed below. That is, let $\hat{\beta}_{i}$ denote the $i^{\text {th }}$ index's estimate of the GSE pass-through and let $\hat{\beta}^{*}$ denote the minimum distance estimate of the GSE pass-through. Then the predicted jumbo-conforming spread using the four indexes is

$$
\hat{y}=\sum_{i=1}^{4} w_{i} x_{i} \hat{\beta}_{i}
$$

where $w_{i}$ is the $i^{t h}$ index's weight and $x_{i}$ is the $i^{\text {th }}$ index's GSE debt advantage. The hypothetical jumbo-conforming spread using the minimum distance estimator is

$$
\hat{y}^{*}=x^{*} \hat{\beta}^{*}
$$

where we do not observe $x^{*}$. We therefore substitute $\hat{y}$ in for $\hat{y}^{*}$ and solve for $x^{*}-\mathrm{a}$ weighted average of the $x_{i} \mathrm{~s}-$ so that

$$
\hat{x}^{*}=\sum_{i=1}^{4} w_{i} x_{i} \hat{\beta}_{i} / \hat{\beta}^{*} .
$$

This is an estimate of the GSE debt advantage consistent with our minimum distance estimate of the GSE pass-through. In contrast, the estimated GSE advantage from issuing short-term debt averages 13 basis points, with a standard deviation of 6 basis points. As shown in the middle panel, we estimate that the overall GSE advantage averaged about 40 basis points during the past decade, with a standard deviation of 12 basis points. 
For our calculation of the mortgage rate savings to homeowners, we use our passthrough estimate of 16.4 percent and our weighted-average estimate of the GSE debt advantage. As shown in the lower panel of exhibit 6, this implies that GSE activities typically account for about 6.5 basis points of the difference between jumbo and conforming mortgage rates, with an estimated standard deviation of 1.9 basis points.

\section{Sensitivity Analysis and Interpreting Our Regressions}

As the reader may know, Fannie Mae (2004) and Raines (2004) have commented on our approach in several respects, including our use of a discrete loan-to-value variable, our decision not to include a continuous loan size variable, our limited ability to control for subprime mortgages, and our comparison of GSE funding costs to private corporations instead of swaps. In addition, in two studies sponsored by Fannie Mae, Greene (2004) and Blinder (2004) raise concerns about the robustness and efficiency of our estimates. ${ }^{33}$ We deal with each of these concerns by implementing several alternative specifications. As we show, our results are robust to these alternative specifications - the estimated mortgage rate reduction attributed to these GSEs does not generally increase and may very well be smaller (see exhibits 7-8).

\section{California Only}

As discussed earlier, the MIRS data has a variety of problems. However, the more recent data for California, which has the largest and most complete jumbo market, may avoid some of the problems encountered when using the nationwide data. Thus, we first explore the sensitivity of our results to estimation on this subsample of our data. The average estimate (over time) of the jumbo-conforming spread is a bit larger in the California subsample (17.1 basis points) than in the full sample (16.2 basis points). The minimum distance estimate of the pass-through is also a bit larger in the California subsample (20.8 percent) than in the full sample (16.4 percent). Based on an average

\footnotetext{
${ }^{33}$ In another study commissioned by Fannie Mae, Blinder, Flannery, and Kamihachi (2004) provide a comprehensive critique of our methodology, including additional sensitivity analysis and alternative interpretations of our theoretical and empirical models. Our response to their study is contained in Passmore and Sherlund (2005). We show that the results of this paper are, largely, quite consistent with the results obtained by Blinder, Flannery, and Kamihachi.
} 
weighted GSE debt advantage of 37.9 basis points, we estimate the mortgage rate reduction to be 7.9 basis points for the California subsample. Although a bit larger, this is not statistically different from the estimated mortgage rate reduction of 6.5 basis points using the full sample.

\section{Measuring Loan-to-Value Ratios}

Second, Fannie Mae (2004) raises concerns about our use of discrete loan-tovalue variables. In lieu of the indicator variables employed in our original specification, we use the continuous loan-to-value ratio, as provided by the MIRS. The average jumboconforming spread is now estimated to be only 14.8 basis points and the minimum distance estimate of the GSE pass-through is 16.7 percent. Based on the average weighted GSE debt advantage of 38.9 basis points, we estimate the mortgage rate reduction to be 6.5 basis points - virtually identical to the results of our original specification.

\section{Adding Loan Size as an Explanatory Variable}

Many researchers have used loan size as an explanatory variable in the first-step regression, even though such a variable is clearly simultaneously determined with mortgage rates. Moreover, researchers rarely adjust their measure of the jumboconforming spread for its interaction with the loan size variable. We will discuss whether loan size should be included as an explanatory variable in the following section. Here, we focus on how to interpret the results correctly once loan size is included in the firststep regression. Fannie Mae (2004) presents estimates of the jumbo-conforming spread using loan size as an explanatory variable. Indeed, one can show that the average treatment effect, or the jumbo-conforming spread in this case, is just the conditional difference between average mortgage rates in the jumbo and conforming markets. This is exactly what the model without the continuous loan size variable estimates. When one includes the loan size as an explanatory variable, the resulting estimate of the jumboconforming spread essentially double counts the decrease in mortgage rates arising because of a larger loan size, which must then be subtracted off to calculate the average treatment effect of jumbo-conforming status. 
When we introduce loan size as an additional explanatory variable in the first-step regressions, the average estimate of the coefficient on the jumbo-conforming dummy under this specification increases substantially to 27.8 basis points. However, when we account for the double counting described above, the estimate of the jumbo-conforming spread for average conforming versus average jumbo mortgages is still 16.2 basis points (the end results, therefore, are identical to those of our original specification). However, erroneously using the coefficient on the jumbo dummy instead of the corrected measure for the jumbo-conforming spread yields a minimum distance estimate of the GSE passthrough of only 7.8 percent. Multiplied by the average weighted GSE debt advantage of 42.4 basis points gives an estimated mortgage rate reduction of only 3.3 basis points. The decrease in the estimated GSE pass-through under this approach more than offsets the perceived increase in the estimated coefficient on the jumbo dummy variable.

\section{Controlling for Subprime Mortgages}

To control for the possible presence of subprime mortgage loans in our data, we first restrict our sample to contain only mortgage loans with loan-to-value ratios less than or equal to 80 percent. This approach yields an estimated jumbo-conforming spread of 14.4 basis points and a minimum distance pass-through estimate of 10.6 percent. The average weighted GSE debt advantage is 42.5 basis points, implying an estimated mortgage rate reduction of 4.5 basis points. This estimate is lower than, but not statistically different from, the estimate from our original specification.

Next, taking a more direct approach to control for possible subprime loans, we treat any non-jumbo mortgage with a mortgage rate in the top ten percent of non-jumbo mortgage rates as subprime by including an indicator variable in the first-step regressions. ${ }^{34}$ This method increases the estimated jumbo-conforming spread to 22.7 basis points, but the minimum distance estimate of the pass-through decreases to 13.8 percent. The average weighted GSE debt advantage is 38.6 basis points, implying an

\footnotetext{
${ }^{34}$ The MIRS survey is voluntary and the Federal Housing Finance Board, which runs the survey, does not make public the institutions that participate. However, given the history of the survey, it seems unlikely that it includes any subprime lenders.
} 
estimated mortgage rate reduction of 5.3 basis points. Once again, this is not statistically different from the results of our original specification.

Taking a different approach, we treat any mortgage loan with a spread to the 10year Treasury rate of 300 basis points or more as subprime by including an indicator variable in the first-step regressions. The average jumbo-conforming spread under this approach is 13.9 basis points and the minimum distance estimate of the GSE passthrough is 11.3 percent. Multiplied by the average weighted GSE debt advantage of 41.0 basis points gives an estimated mortgage rate reduction of 4.6 basis points. As before, this point estimate is not statistically different from that of our original specification.

\section{Interpreting the Jumbo-Conforming Dummy Variable}

Greene (2004) raises several concerns with the econometric specification and techniques we employ. First, he cites an ambiguity in measuring the jumbo-conforming spread. In our regression analysis, we include indicator variables for both jumbo loans and for smaller loans (with principal balances less than $\$ 100,000$ ). The estimated coefficients on these two indicator variables therefore reflect the premium (or discount) in pricing these types of loans relative to moderately-sized (neither small nor jumbo) loans. Our average estimate of the coefficient on the jumbo loan indicator variable is about 16 basis points - which we call the jumbo-conforming spread, since it measures the pricing difference between moderately-sized and jumbo loans.

Greene correctly points out, however, that an ambiguity arises because of the inclusion of the small loan indicator variable. If we want to compare small loans with jumbo loans, we need to take into account not only the estimated effect of jumbo status, but the effect of small-loan status as well. Our average estimate of the coefficient on the small loan indicator variable is 14 basis points indicating that small loans cost, on average, 14 basis points more than comparable moderately-sized loans, implying that the jumbo-conforming spread for small loans is only 2 basis points. Thus, for a generic conforming loan (either small or moderately-sized) the jumbo-conforming spread lies between 2 and 16 basis points. We believe that comparing moderately-sized loans to jumbo loans gives a better comparison for understanding the effect of GSEs, mainly because generally higher small loan rates might reflect diseconomies of scale. 


\section{Inefficiency and Two-Step Estimation}

Greene also cites potential bias and inefficiency in estimation that may lead to "seriously flawed results." Efficiency is not an argument about whether or not our coefficients are accurate, but instead about the effective use of the information provided within the sample. We argue that our estimates are not necessarily inefficient given the underlying data structure. We conduct what is called multilevel data analysis - analysis on some data that are micro-level (individual loans) and other data that are macro-level (monthly macro variables). In this context, all that is needed in terms of efficiency, we believe, is large group sizes (number of loans per month) and a relatively small number of groups (total number of months), both of which are satisfied with the MIRS data. ${ }^{35}$

Greene seems to believe that our econometric specification focuses on the firststep equation and therefore falls within a random coefficients framework. Instead, our analysis actually focuses on the second-step equation, in which estimates of the jumboconforming spread are regressed against the GSE debt advantage and other variables reflecting risk and economic conditions. This equation requires some estimate of the jumbo-conforming spread, which, in our analysis, we derive from the first-step estimation.

However, to address the concern with potential bias and inefficiency due to twostep estimation (Greene, 2004), we calculate the jumbo-conforming spread as the difference between mean jumbo and conforming mortgage rates for each month and state and include monthly averages of the first-step explanatory variables as additional explanatory variables in estimating the second-step regression - thereby avoiding the first-step regressions altogether. The average jumbo-conforming spread under this approach is 12.7 basis points and the minimum distance pass-through estimate is 13.6 percent. Multiplying by the average weighted GSE debt advantage of 36.9 basis points leads to a mean mortgage rate reduction of 5.0 basis points. Again, our original specification seems robust to this alternative specification and estimation methodology.

\footnotetext{
${ }^{35}$ Note that we already adjust our standard errors to account for heteroskedasticity, first-order autocorrelation, and clustering by month.
} 
Interpreting the GSE Implicit Subsidy Pass-Through to Mortgage Rates

Blinder (2004) discusses the random component to estimation, i.e., the range of parameter estimates implied by standard errors, which underlies all economic analysis. In particular, he is concerned that "the range of uncertainty is large." However, the range of uncertainty is not large enough for us to believe that the GSEs' entire implicit subsidy is passed through to mortgage rates. Our estimate of the GSE pass-through is 16.4 percent, with a standard error of 9.2 percentage points. We can therefore easily reject the hypothesis that the implied subsidy is passed through in its entirety to homeowners via reduced mortgage rates. Note, however, that we cannot reject the hypothesis that none of the subsidy is passed through to homeowners at conventional confidence levels.

Blinder also argues that the GSE funding advantage is not a product of the implicit subsidy alone, that the jumbo-conforming spread is not due to the GSE funding advantage alone, and that homeownership rates are not only affected through mortgage rates. Our estimation attempts to control for economies of scale and efficiency found in the conforming MBS market (to remove this effect from the GSE funding advantage) and models the jumbo-conforming spread as not only a function of the GSE debt advantage, but other variables as well, to account for the GSEs' business operations and overall economic conditions. We agree with Blinder that one must try to distinguish between the mortgage rate reductions generated by the business operations of an effective and efficient mortgage securitizer from those generated by the GSE subsidy.

\section{Debt Advantage Relative to Swap Yields}

Fannie Mae (2004) suggested that the GSE funding advantage be measured by comparing their funding costs to the swap yield curve. The swap yield curve, however, does not represent any particular institution's funding costs, particularly over a long time horizon. The swap yield curve is derived from three month LIBOR. For example, the 10-year swap yield is the yield one could expect to pay if one could issue three-month debt at LIBOR regularly at three-month intervals over the next ten years. The British Banker's Association computes LIBOR, which represents the unsecured debt costs at 
short maturities of an average bank in the Association's panel. ${ }^{36}$ The criteria for inclusion in the panel are not public, but a bank must have a high credit standing and be a major participant in interbank cash and forward markets. Bank of America, Citibank, and JP Morgan Chase are American banks that are currently included in the panel.

Using data from Lehman, we construct spread to swap series for Bank of America (BAC), Wells Fargo (WFC), and Fannie Mae (FNM) for January 2001 through May 2003. These series, along with the jumbo-conforming spread, are depicted in the upper panel of exhibit 9. As shown, Fannie Mae's funding advantage relative to swaps first became negative in 2001 and then again in 2002. Bank of America and Wells Fargo had much larger spreads to swaps than Fannie Mae did.

We consider regressions of two forms: One using the corporate-swap and swapagency spreads as distinct explanatory variables, and the other using the corporate-agency spread. ${ }^{37}$ Each regression also controls for risk and pricing characteristics, as in our original analysis. As shown in exhibit 9, the swap-agency spread has a much larger effect than the corporate-swap spread on the jumbo-conforming spread, though both effects are statistically indistinguishable from zero (but different from one) at conventional confidence levels. The corporate-agency spread also has a statistically negligible impact on the jumbo-conforming spread.

These results suggest that Fannie Mae may indeed price mortgages as a spread to swaps. However, this spread does not capture the debt advantage resulting from the implicit subsidy and therefore is not the proper comparison to make. When we do draw the proper comparison, we find that little or none of the debt advantage is passed through to homeowners in the form of lower mortgage rates.

\section{A Note on Specification of the First-Step Regressions}

Because mortgage rates exhibit discrete jumps at various loan-to-value and loan size thresholds, we show that inclusion of a continuous variable itself may lead to biased

\footnotetext{
${ }^{36}$ The "U.S. Dollar" panel contains 16 banks. The banks report their funding costs at 11:00 a.m. each day. The yields reported by the highest four and lowest four banks are thrown out and the yields of the middle eight banks are averaged to create "LIBOR."

${ }^{37}$ We do not use only the swap-agency spread because this ignores the bulk of the implicit subsidy. We therefore include the corporate-swap spread as an additional explanatory variable.
} 
and inconsistent estimates of the jumbo-conforming spread (as well as other parameters). We argue that "economies of scale" is not sufficiently controlled for through the inclusion of individual loan sizes. Finally, because mortgage rates and loan sizes are simultaneously determined, regressing mortgage rates on loan sizes is subject to endogeneity concerns and thus potentially biased parameter estimates. We address each of these points in turn.

We use indicator variables instead of continuous loan-to-value ratio and loan size variables in our first-step regressions primarily because mortgage rates exhibit discrete jumps at certain loan-to-value (e.g., $L T V=0.80$ ) and loan size (e.g., at the conforming loan limit) thresholds. Failure to account for such jumps could lead to not only inconsistent estimates of the marginal effect of loan-to-value ratios and/or loan sizes on mortgage rates, but also an inconsistent estimate of our parameter of interest - the jumboconforming spread. ${ }^{38}$ To see this, consider the following thought experiment. About 62 percent of loans in the conforming market have loan-to-value ratios less than 0.80 , compared to about 82 percent of loans in the jumbo market. Clearly then, the loan-tovalue ratio will be correlated with jumbo-conforming status. Therefore, any specification error resulting from the loan-to-value ratio will likely also be correlated with jumboconforming status. This results in correlation between the jumbo-conforming status variable and the composite error term (a mixture of standard statistical noise and specification error), violating a key assumption of the classical regression model and invalidating the consistency result from asymptotic theory. A similar result holds for the loan size variable. We can actually see these effects in exhibit 7 - the average estimates of the jumbo-conforming spread change quite a bit once the continuous loan size variable is introduced. Additionally, the effect of loan size is often ignored in calculating the effect of jumbo-conforming status (most studies only report the estimate on the jumbo indicator variable and do not consider the necessary increase in loan size to achieve jumbo status).

Next, many prior studies have included loan size as an explanatory variable to reflect economies of scale. Economies of scale, however, are not realized on individual

\footnotetext{
${ }^{38}$ Further, failure to account for these discrete jumps may lead to inconsistent parameter estimates for any parameter correlated with loan-to-value ratios or loan sizes.
} 
loan sizes (do originators really line up borrowers and start with the smallest loan sizes?) - instead, they are realized at the aggregate margin. We control for this aspect in the second step of our analysis, allowing economies of scale to differ between the jumbo and conforming markets, through aggregate demand and market development variables and, to some extent, the state- and time-specific intercept terms in the first-step regressions. Further, the traditional modeling of economies of scale requires the inclusion of not only loan size, but higher-order terms of loan size as explanatory variables.

Finally, putting aside our two prior points, loan size is an endogenous variable. Therefore, including loan size as an explanatory variable (without instrumentation) leads to biased and inconsistent parameter estimates. We therefore take a dual approach considering input and output prices instead of loan size (much akin to estimating cost or

profit functions instead of production functions in production analysis). One could think of the dual approach as a reduced-form regression, with input and output prices acting as instruments for the loan size. We include input and output prices in the second-step regression, in which we estimate the effects of input prices on the jumbo-conforming spread.

\section{Conclusions}

In this paper, we derive a theoretical model of how jumbo and conforming mortgage rates are determined and how the jumbo-conforming spread might arise. We show that mortgage rates reflect the cost of funding mortgages and that this cost of funding can drive a wedge between jumbo and conforming rates (the jumbo-conforming spread) because the two markets may have different funding costs. Further, we show how the jumbo-conforming spread tightens when mortgage demand is low, core deposits are sufficient to fund mortgage demand, and as the mortgage market become more liquid and realizes economies of scale.

Using MIRS data for April 1997 through May 2003, we estimate the jumboconforming spread to be 15-18 basis points. Further, we find that GSEs pass through only about 16 percent of their 40 basis point debt advantage, lowering homeowners' mortgage rates by 7 basis points. This result provides evidence that the jumboconforming spread provides only an upper bound for the amount that GSEs lower 
mortgage rates. That is, the GSE funding advantage accounts for 7 basis points of the 1518 basis point jumbo-conforming spread. 


\section{References}

Ambrose, B. and R. Buttimer (2004). "GSE Impact on Rural Mortgage Markets," Regional Science and Urban Economics, forthcoming.

Ambrose, B., R. Buttimer, and T. Thibodeau (2001). "A New Spin on the JumboConforming Loan Rate Differential," Journal of Real Estate Finance and Economics, 23, 309-336.

Ambrose, B., M. LaCour-Little, and A. Sanders (2002). "The Effect of Conforming Loan Status on Mortgage Yield Spreads: A Loan Level Analysis," mimeo from authors, November 3, 2003.

Ambrose, B. and T. Thibodeau (2004). "Have the GSE Affordable Housing Goals Increased the Supply of Mortgage Credit," Regional Science and Urban Economics, 34, 263-273.

Blinder, A.S. (2004). Letter on Federal Reserve Working Paper to CEO Raines from Dr. Alan S. Blinder.

Blinder, A.S., M.J. Flannery, and J.D. Kamihachi (2004). "The Value of HousingRelated Government Sponsored Enterprises: A Review of a Preliminary Draft Paper by Wayne Passmore," Fannie Mae.

Bolder, D. and D. Stréliski (1999). "Yield Curve Modeling at the Bank of Canada," Technical Report No. 84, Bank of Canada.

Congressional Budget Office (2001). Federal Subsidies and the Housing GSEs, Washington, D.C.: Government Printing Office.

Cotterman, R. and J. Pearce (1996). "The Effects of the Federal National Mortgage Association and the Federal Home Loan Mortgage Corporation on Conventional FixedRate Mortgage Yields" in Studies on Privatizing Fannie Mae and Freddie Mac, Washington, D.C.: U.S. Department of Housing and Urban Development, 97-168.

Fannie Mae (2004). Preliminary Response to Wayne Passmore Federal Reserve Working Paper: 'The GSE Implicit Subsidy and Value of Government Ambiguity.'

Goldberger, A.S. (1991). A Course in Econometrics, Cambridge, MA: Harvard University Press.

Goodman, J.L., Jr., and W. Passmore (1992). "Market Power and the Pricing of Mortgage Securitization," Federal Reserve Board Finance and Economics Discussion Series, 187, 1-31. 
Greene, W.H. (2004). Commentary on 'The GSE Implicit Subsidy and Value of Government Ambiguity.'

Hendershott, P. and J. Shilling (1989). "The Impact of Agencies on Conventional FixedRate Mortgage Yields," Journal of Real Estate Finance and Economics, 2, 101-115.

Hermalin, B. and D. Jaffee (1996). "The Privatization of Fannie Mae and Freddie Mac: Implications for Mortgage Industry Structure," in Studies on Privatizing Fannie Mae and Freddie Mac, Washington, D.C.: U.S. Department of Housing and Urban Development, 225-302.

Heuson, A., W. Passmore, and R. Sparks (2001). "Credit Scoring and Mortgage Securitization: Implications for Mortgage Rates and Credit Availability," Journal of Real Estate Finance and Economics, 23, 337-364.

Jaffee, D. (2003). "The Interest Rate Risk of Fannie Mae and Freddie Mac," Journal of Financial Services Research, 24, 5-29.

McKenzie, J. (2002). "A Reconsideration of the Jumbo/Non-Jumbo Mortgage Rate Differential," Journal of Real Estate Finance and Economics, 25, 197-213.

Mankiw, N.G. (2003). Remarks at the Conference of State Bank Supervisors, State Banking Summit and Leadership Conference, November 6, 2003.

Naranjo, A. and A. Toevs (2002). "The Effects of Purchases of Mortgages and Securitization by Government Sponsored Enterprises on Mortgage Yield Spreads and Volatility," Journal of Real Estate Finance and Economics, 25, 173-196.

Nelson, C. and A. Siegel (1987). "Parsimonious Modeling of Yield Curves," Journal of Business, 60, 473-489.

Nothaft, F., J. Pearce, and S. Stevanovic (2002). "Debt Spreads Between GSEs and Other Corporations," Journal of Real Estate Finance and Economics, 25, 151-172.

Passmore, W. and S.M. Sherlund (2005). "GSE Subsidy Transmission in Competitive Banking Markets," forthcoming.

Passmore, W. and R. Sparks (1996). "Putting the Squeeze on a Market for Lemons: Government-Sponsored Mortgage Securitization," Journal of Real Estate Finance and Economics, 13, 27-43.

Passmore, W. and R. Sparks (2000). "Automated Underwriting and the Profitability of Mortgage Securitization," Journal of Real Estate Finance and Economics, 28, 285-305.

Passmore, W., R. Sparks, and J. Ingpen (2002). "GSEs, Mortgage Rates and Mortgage Securitization," Journal of Real Estate Finance and Economics, 25, 215-242. 
Raines, F.D. (2004). Testimony before U.S. Committee on Banking, Housing, and Urban Affairs, February 25, 2004.

Sanders, A. (2002). "Government Sponsored Agencies: Do the Benefits Outweigh the Costs?" Journal of Real Estate Economics, 25, 121-127.

Torregrosa, D. (2001). "Interest Rate Differentials Between Jumbo and Conforming Mortgages, 1995-2000," Congressional Budget Office.

U.S. Department of the Treasury (1996). Government Sponsorship of the Federal National Mortgage Association and the Federal Home Loan Mortgage Corporation, Washington, D.C.: Government Printing Office. 
The Jumbo-Conforming Spread

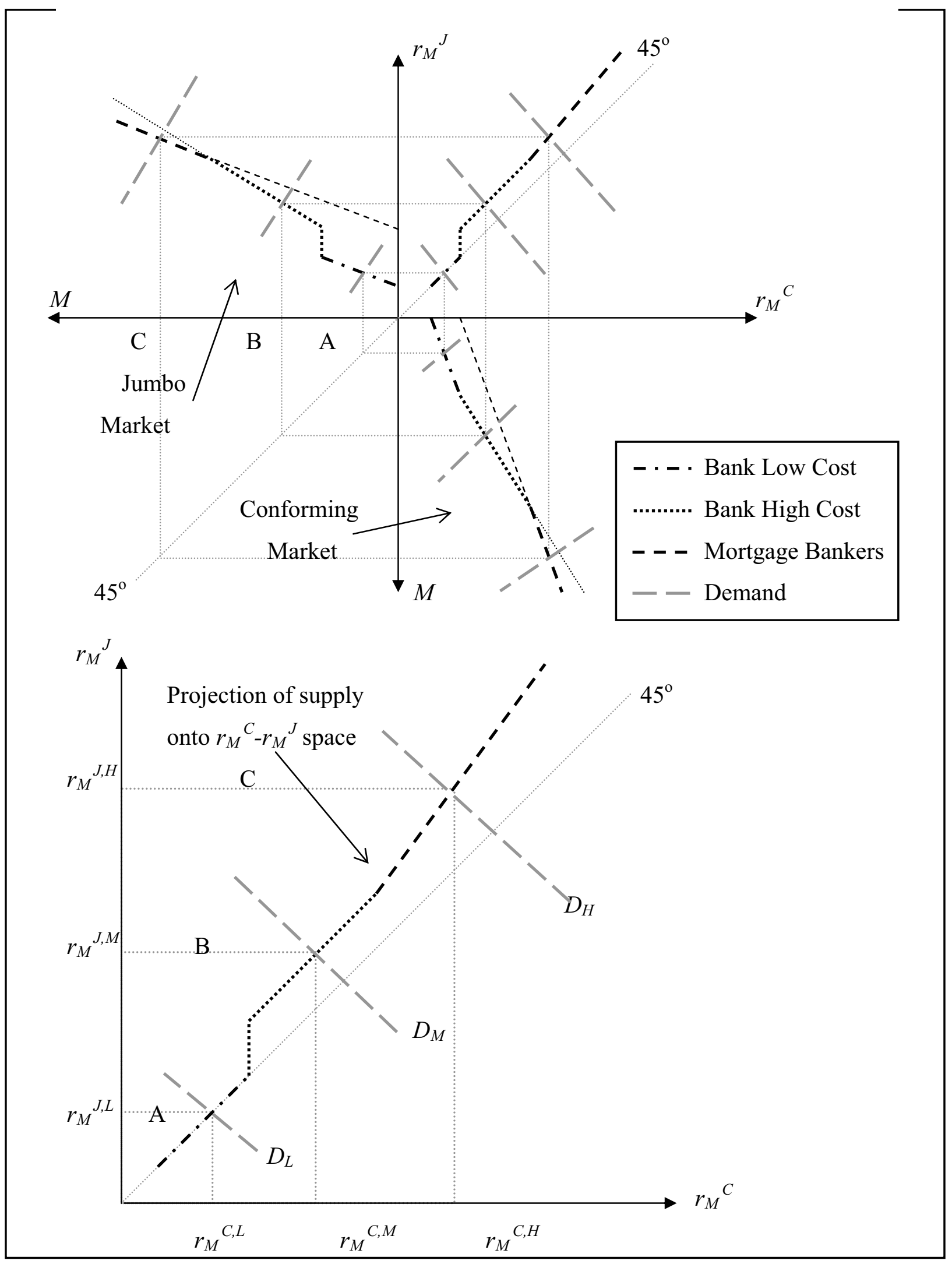


Exhibit 2

\section{Jumbo-Conforming Spread Regression Analysis}

First-Step Regression Results

\begin{tabular}{|c|c|c|c|c|c|}
\hline \multirow[b]{2}{*}{ Symbol } & \multirow[b]{2}{*}{ Description } & \multicolumn{2}{|c|}{ Summary Statistics } & \multicolumn{2}{|c|}{ Regression Estimates* } \\
\hline & & Mean & $\begin{array}{l}\text { Standard } \\
\text { Deviation } \\
\end{array}$ & $\begin{array}{l}\text { Coefficient } \\
\text { Estimate } \\
\end{array}$ & $\begin{array}{c}\text { Standard } \\
\text { Error }\end{array}$ \\
\hline RM & Mortgage rate & 7.23 & 0.79 & & \\
\hline J & Jumbo & 0.06 & 0.23 & 0.16 & 0.05 \\
\hline $\mathrm{LTV}_{1}$ & LTV $75 \%-80 \%$ & 0.36 & 0.48 & 0.03 & 0.04 \\
\hline $\mathrm{LTV}_{2}$ & LTV $81 \%-90 \%$ & 0.15 & 0.35 & 0.17 & 0.05 \\
\hline $\mathrm{LTV}_{3}$ & LTV above $90 \%$ & 0.22 & 0.41 & 0.15 & 0.04 \\
\hline NEW & New home purchase & 0.17 & 0.38 & 0.05 & 0.04 \\
\hline SMALL & $\begin{array}{l}\text { Small mortage (principal }< \\
\$ 100,000)\end{array}$ & 0.27 & 0.44 & 0.14 & 0.04 \\
\hline FEES & Mortgage has fees & 0.62 & 0.52 & 0.06 & 0.03 \\
\hline MTGCO & $\begin{array}{l}\text { Originated by a mortgage } \\
\text { company }\end{array}$ & 0.67 & 0.47 & 0.12 & 0.05 \\
\hline \multicolumn{4}{|l|}{$\mathrm{R}^{2}$} & \multicolumn{2}{|c|}{0.77} \\
\hline \multicolumn{6}{|c|}{$\begin{array}{l}\text { Note. Data from the FHFB Mortgage Interest Rate Survey (MIRS) from April } 1997 \text { through May } 2003 . \\
\text { Includes only loans whose principal amounts are between } \$ 50,000 \text { and twice the conforming loan limit } \\
\text { for that year. In total, there are } 1,036,252 \text {. observations. }\end{array}$} \\
\hline
\end{tabular}

${ }^{*}$ Average over 370 regressions

Estimated Jumbo-Conforming Spread From Monthly Regressions **

\begin{tabular}{llcc} 
State & $\begin{array}{c}\text { Mean } \\
\text { (Basis Points) }\end{array}$ & $\begin{array}{c}\text { Standard } \\
\text { Deviation }\end{array}$ \\
\hline California & 17.1 & 9.3 \\
New Jersey & 14.8 & 9.9 \\
Maryland & 18.1 & 12.0 \\
Virginia & 16.0 & 10.6 \\
Other States & 15.0 & 9.1 \\
& &
\end{tabular}

** Mean and standard deviation of coefficients for the 370 regression estimates.
Jumbo-Conforming Spread

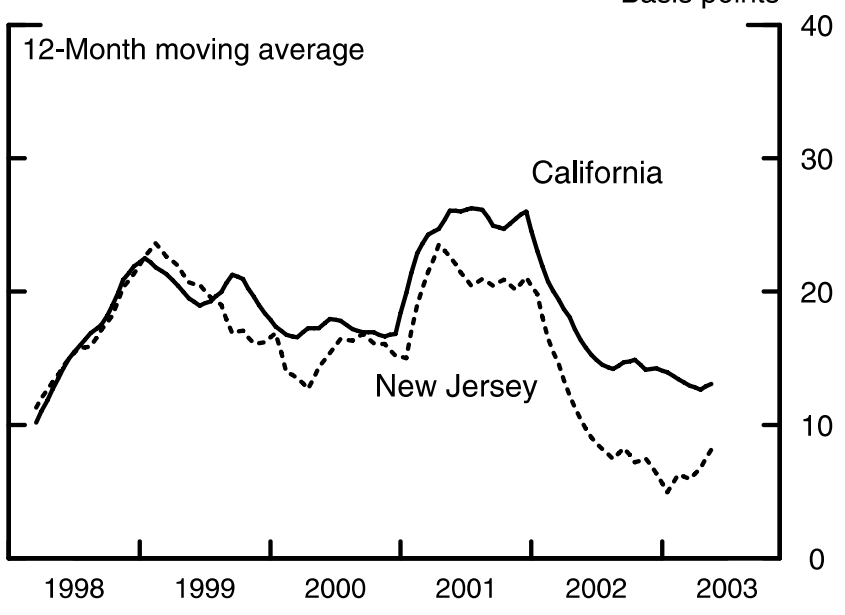

Source: First-step regressions. 
Exhibit 3

GSE Debt Advantages

\section{Long-Term GSE Debt Advantages}

Basis Points

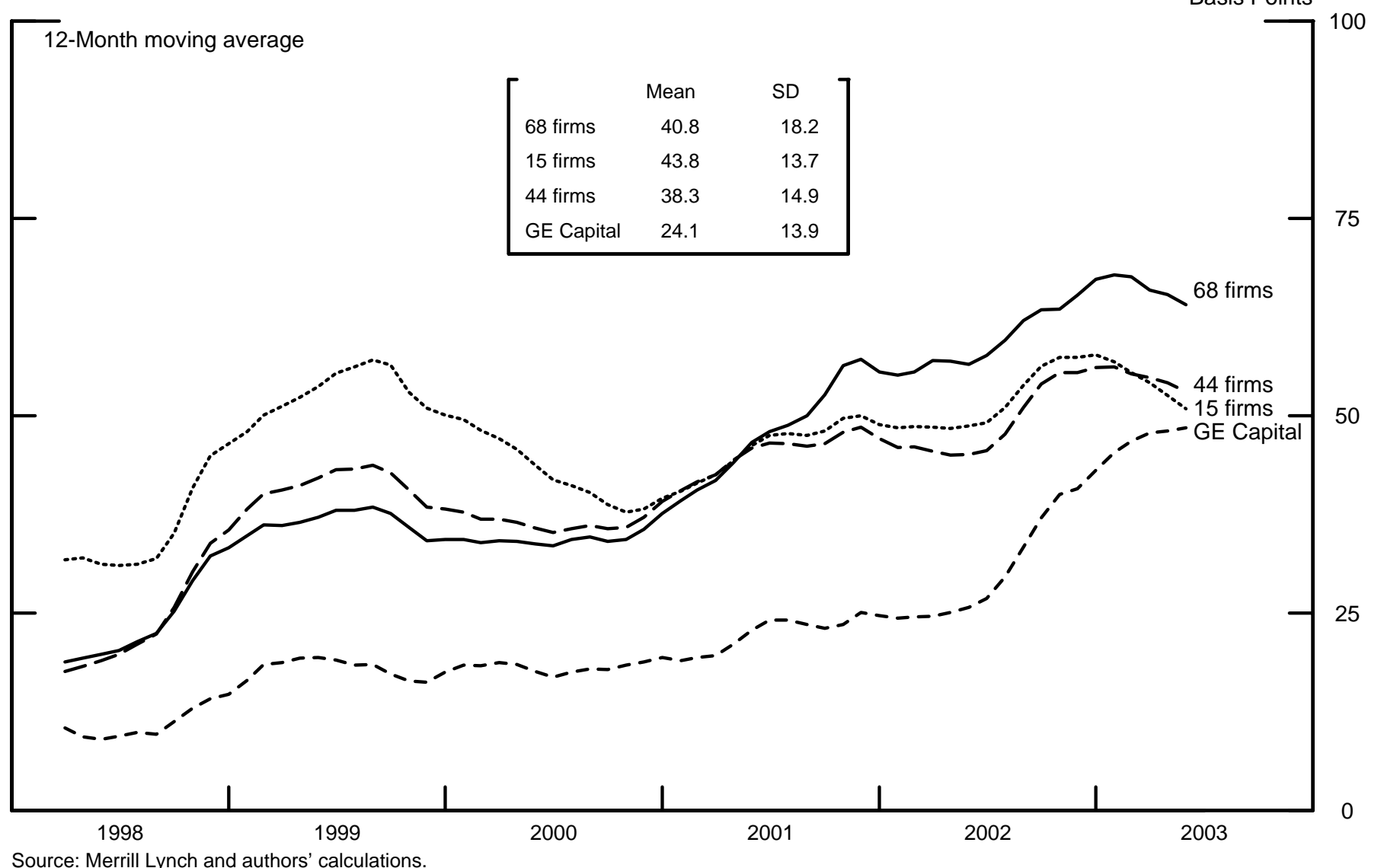

Source: Merrill Lynch and authors' calculations.

Short-Term GSE Debt Advantage

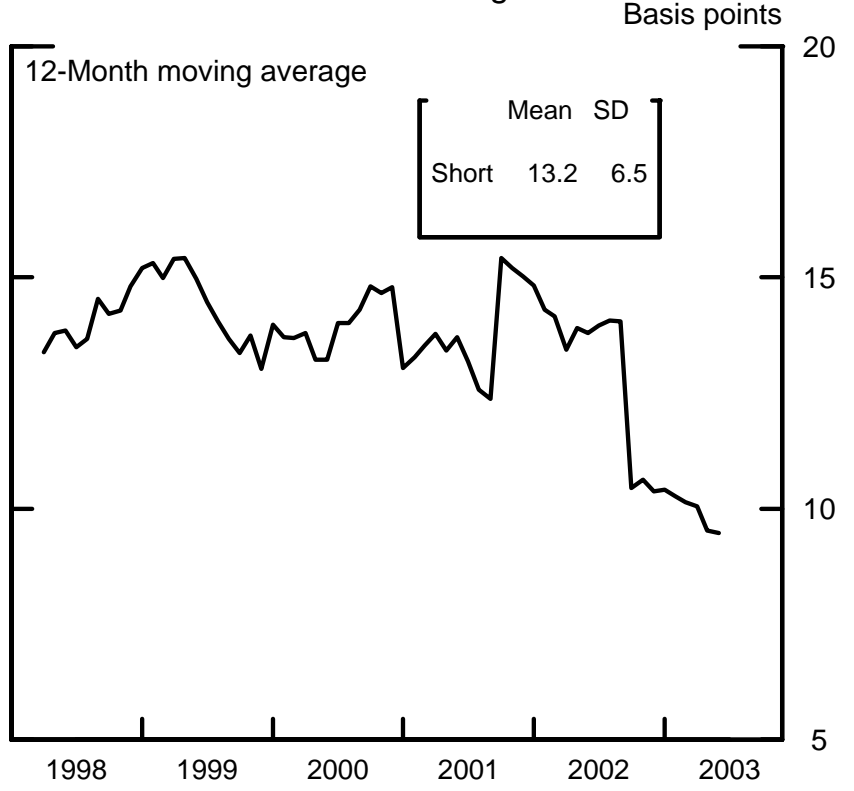

Source: Merrill Lynch (corporate and bond data), Bloomberg (repo and discount rates).
Debt to Mortgage Portfolio Ratio

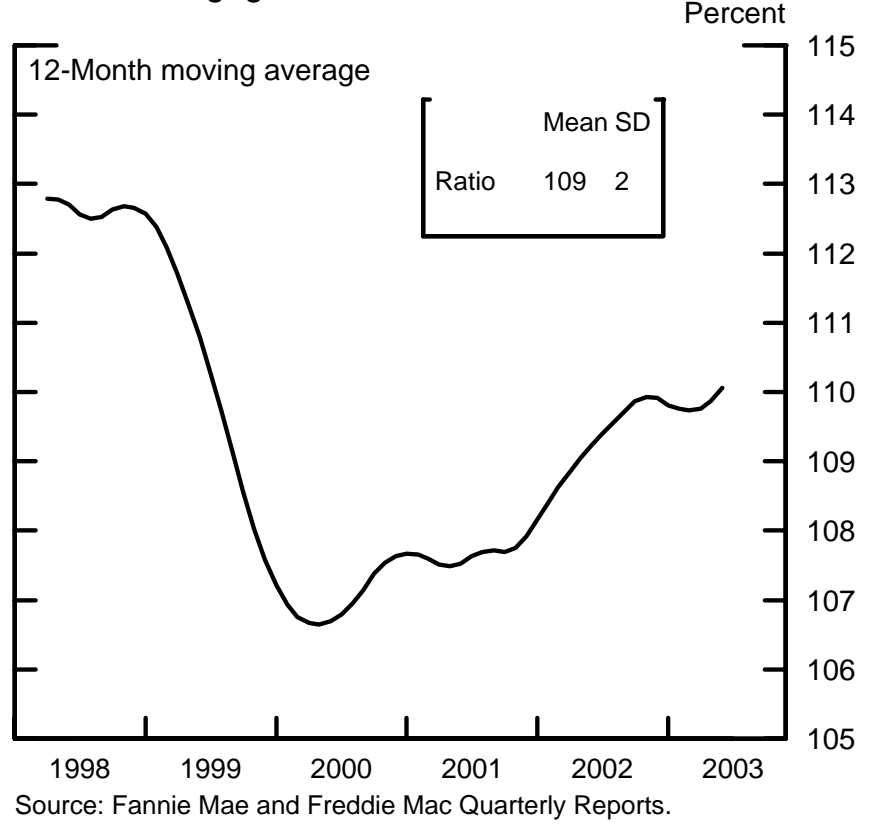




\section{Exhibit 4 \\ Variables Used in Regression Analysis}

\section{Summary Statistics}

\begin{tabular}{|c|c|c|c|}
\hline Symbol & Description & Mean & $\begin{array}{l}\text { Standard } \\
\text { Deviation }\end{array}$ \\
\hline$\alpha_{1}$ & JC Spread & 0.16 & 0.10 \\
\hline $\mathrm{GA}_{68}$ & GSE funding advantage (68 firms) & 0.40 & 0.16 \\
\hline $\mathrm{GA}_{15}$ & GSE funding advantage (15 firms) & 0.43 & 0.12 \\
\hline $\mathrm{GA}_{44}$ & GSE funding advantage (44 firms) & 0.37 & 0.13 \\
\hline $\mathrm{GA}_{\mathrm{GE}}$ & GSE funding advantage (GE Capital) & 0.23 & 0.13 \\
\hline RT & One year treasury rate & 4.29 & 1.65 \\
\hline $\mathrm{CR}$ & Credit risk & 1.93 & 0.89 \\
\hline PR & Prepayment risk & 0.78 & 0.33 \\
\hline $\mathrm{MR}_{68}$ & Maturity-mismatch risk (68 firms) & 0.21 & 0.18 \\
\hline $\mathrm{MR}_{15}$ & Maturity-mismatch risk (15 firms) & 0.11 & 0.26 \\
\hline $\mathrm{MR}_{44}$ & Maturity-mismatch risk (44 firms) & 0.21 & 0.19 \\
\hline$M R_{G E}$ & Maturity-mismatch risk (GE Capital) & 0.35 & 0.19 \\
\hline DEM & Aggregate mortgage demand & 0.16 & 0.02 \\
\hline LTRT & Ten year treasury rate & 5.33 & 0.78 \\
\hline CAP & Mortgage market capacity & 0.01 & 0.00 \\
\hline DEV & Mortgage market development & 0.38 & 0.21 \\
\hline $\mathrm{S}_{1}$ & California & 0.20 & 0.40 \\
\hline $\mathrm{S}_{2}$ & Maryland & 0.20 & 0.40 \\
\hline $\mathrm{S}_{3}$ & New Jersey & 0.20 & 0.40 \\
\hline $\mathrm{S}_{4}$ & Virginia & 0.20 & 0.40 \\
\hline QTR $_{1}$ & Quarter 1 & 0.24 & 0.43 \\
\hline $\mathrm{QTR}_{2}$ & Quarter 2 & 0.27 & 0.44 \\
\hline $\mathrm{QTR}_{3}$ & Quarter 3 & 0.24 & 0.43 \\
\hline
\end{tabular}


Exhibit 5

\section{Regression Results}

Second-Step Regression Results

\begin{tabular}{|c|c|c|c|c|c|c|c|c|c|}
\hline \multirow[b]{2}{*}{ Symbol } & \multirow[b]{2}{*}{ Description } & \multicolumn{2}{|c|}{68 Firms } & \multicolumn{2}{|c|}{15 Firms } & \multicolumn{2}{|c|}{44 Firms } & \multicolumn{2}{|c|}{ GE Capital } \\
\hline & & Coeff. & $\begin{array}{l}\text { Std. } \\
\text { Error }\end{array}$ & Coeff. & $\begin{array}{l}\text { Std. } \\
\text { Error }\end{array}$ & Coeff. & $\begin{array}{l}\text { Std. } \\
\text { Error }\end{array}$ & Coeff. & $\begin{array}{l}\text { Std. } \\
\text { Error }\end{array}$ \\
\hline$\beta_{\circ}$ & Constant & 0.83 & 0.32 & 0.67 & 0.31 & 0.98 & 0.31 & 0.27 & 0.36 \\
\hline GA & GSE funding advantage & 0.07 & 0.11 & 0.31 & 0.11 & 0.17 & 0.10 & 0.10 & 0.11 \\
\hline $\begin{array}{l}\text { RT } \\
\text { CR } \\
\text { PR }\end{array}$ & $\begin{array}{l}\text { One year treasury rate } \\
\text { Credit risk } \\
\text { Prepayment risk }\end{array}$ & $\begin{array}{l}0.05 \\
0.05 \\
0.04\end{array}$ & $\begin{array}{l}0.05 \\
0.04 \\
0.13\end{array}$ & $\begin{array}{l}0.07 \\
0.09 \\
0.24\end{array}$ & $\begin{array}{l}0.03 \\
0.04 \\
0.12\end{array}$ & $\begin{array}{l}0.06 \\
0.05 \\
0.09\end{array}$ & $\begin{array}{l}0.04 \\
0.04 \\
0.12\end{array}$ & $\begin{array}{l}0.07 \\
0.05 \\
0.10\end{array}$ & $\begin{array}{l}0.04 \\
0.04 \\
0.13\end{array}$ \\
\hline MR & Maturity-mismatch risk & 0.22 & 0.17 & 0.52 & 0.14 & 0.35 & 0.16 & 0.26 & 0.09 \\
\hline DEM & Aggregate mortgage demand & 7.09 & 2.56 & 6.69 & 1.93 & 7.19 & 2.12 & 7.98 & 2.07 \\
\hline LTRT & Ten year treasury rate & -0.11 & 0.04 & -0.09 & 0.03 & -0.13 & 0.04 & -0.09 & 0.04 \\
\hline CAP & Mortgage market capacity & -83.51 & 17.94 & -94.41 & 14.09 & -94.76 & 14.95 & -72.73 & 16.36 \\
\hline DEV & $\begin{array}{l}\text { Mortgage market } \\
\text { development }\end{array}$ & -1.26 & 0.31 & -1.70 & 0.27 & -1.49 & 0.27 & -1.22 & 0.31 \\
\hline $\mathrm{S}_{1}$ & California & 0.02 & 0.01 & 0.02 & 0.01 & 0.02 & 0.01 & 0.02 & 0.01 \\
\hline $\mathrm{S}_{2}$ & Maryland & 0.03 & 0.01 & 0.03 & 0.01 & 0.03 & 0.01 & 0.03 & 0.01 \\
\hline $\mathrm{S}_{3}$ & New Jersey & 0.01 & 0.01 & 0.01 & 0.01 & 0.01 & 0.01 & 0.01 & 0.01 \\
\hline $\mathrm{S}_{4}$ & Virginia & -0.00 & 0.01 & -0.00 & 0.01 & -0.00 & 0.01 & -0.00 & 0.01 \\
\hline $\mathrm{QTR}_{1}$ & Quarter 1 & 0.00 & 0.02 & 0.00 & 0.02 & 0.00 & 0.02 & 0.00 & 0.02 \\
\hline $\mathrm{QTR}_{2}$ & Quarter 2 & -0.04 & 0.02 & -0.03 & 0.02 & -0.03 & 0.02 & -0.03 & 0.02 \\
\hline $\mathrm{QTR}_{3}$ & Quarter 3 & -0.06 & 0.02 & -0.05 & 0.02 & -0.06 & 0.02 & -0.06 & 0.02 \\
\hline $\mathrm{R}^{2}$ & & & 0.38 & & .43 & & .40 & & .40 \\
\hline Weight & & & 0.37 & & .32 & & .15 & & .16 \\
\hline
\end{tabular}

Minimum Distance Estimate of the GSE Pass-Through

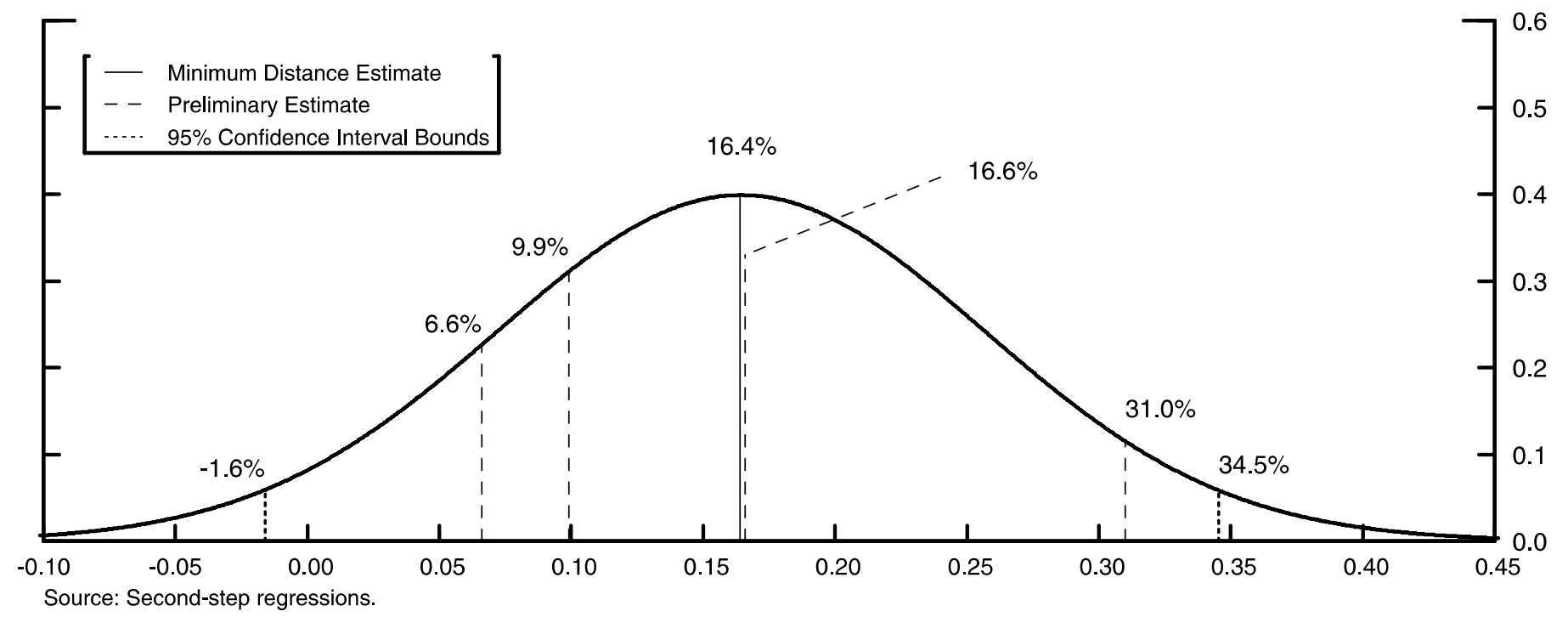


Exhibit 6

\section{Mortgage Rate Reduction}

GSE Debt Advantage by Parts

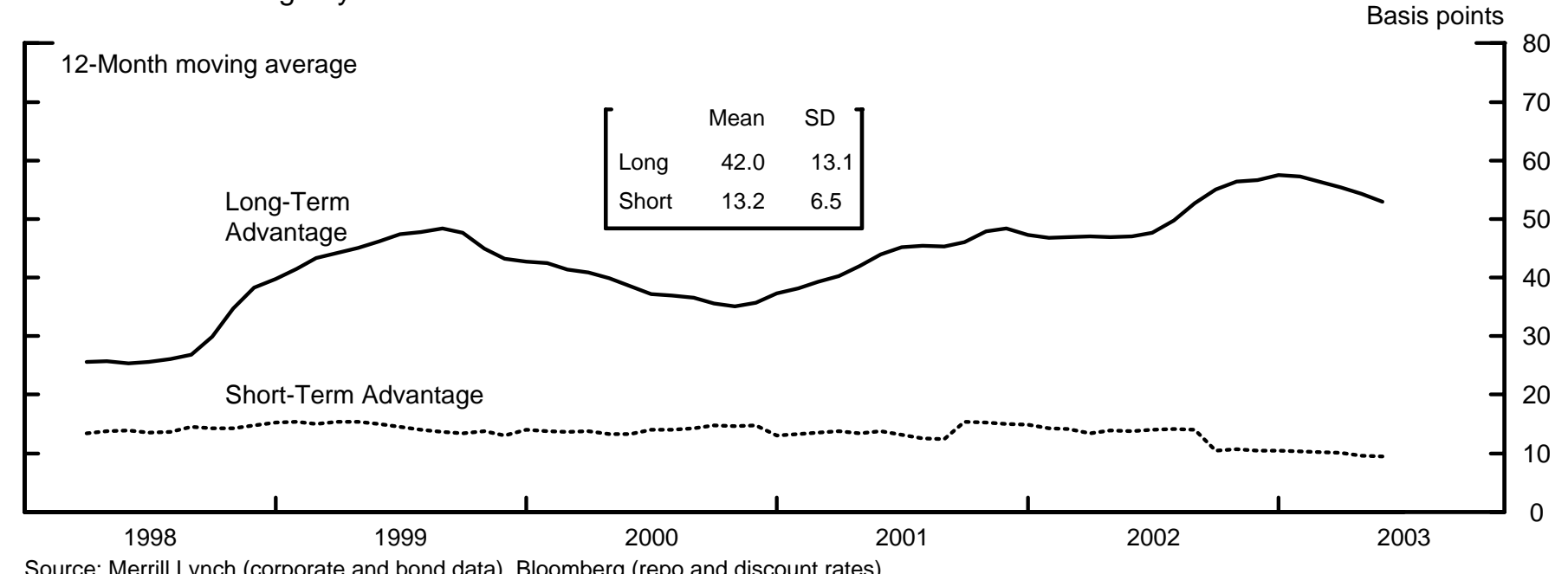

Source: Merrill Lynch (corporate and bond data), Bloomberg (repo and discount rates).

GSE Weighted Debt Advantage

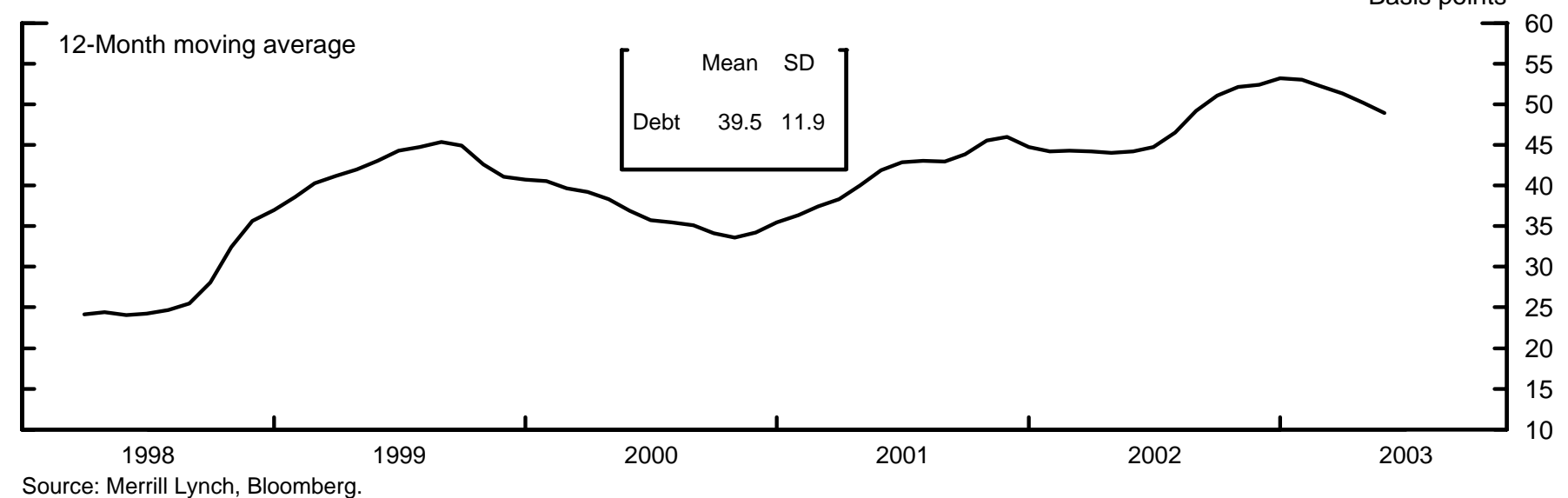

Source: Merrill Lynch, Bloomberg.

Estimated GSE Mortgage Rate Reductions

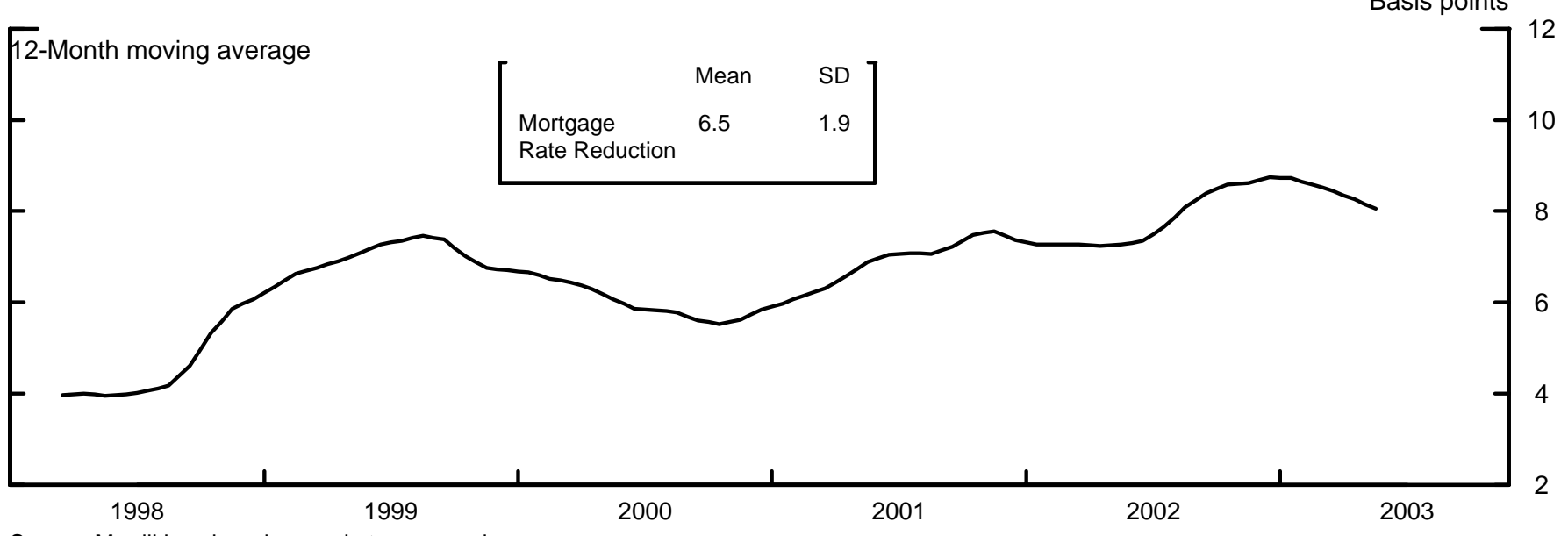

Source: Merrill Lynch and second-step regressions. 


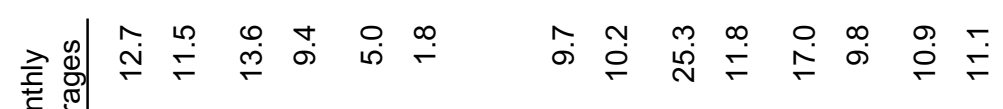

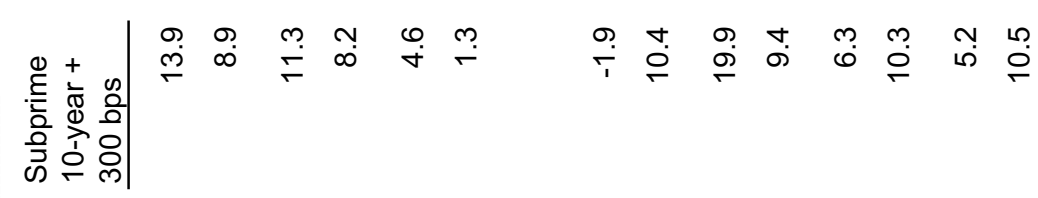

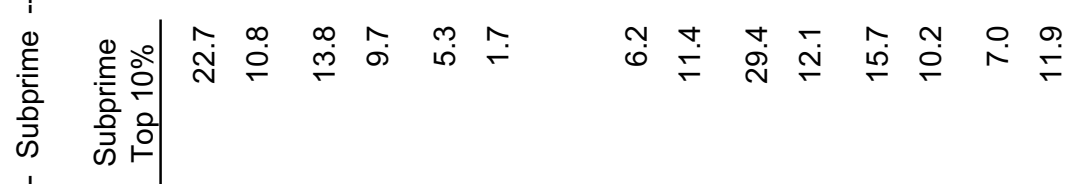

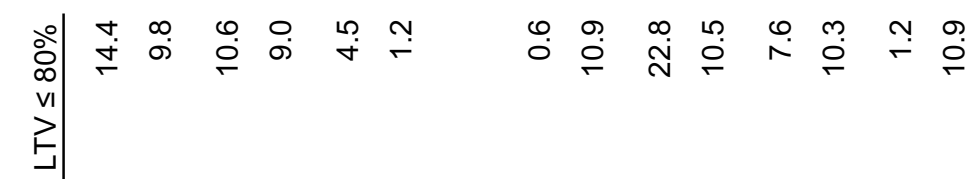

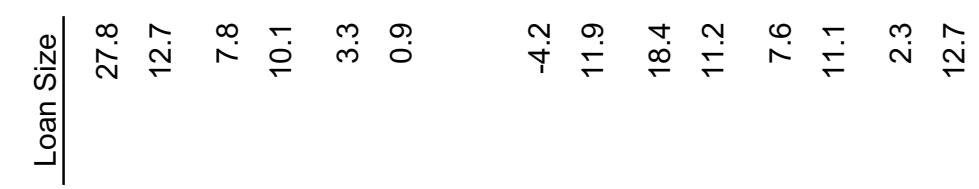

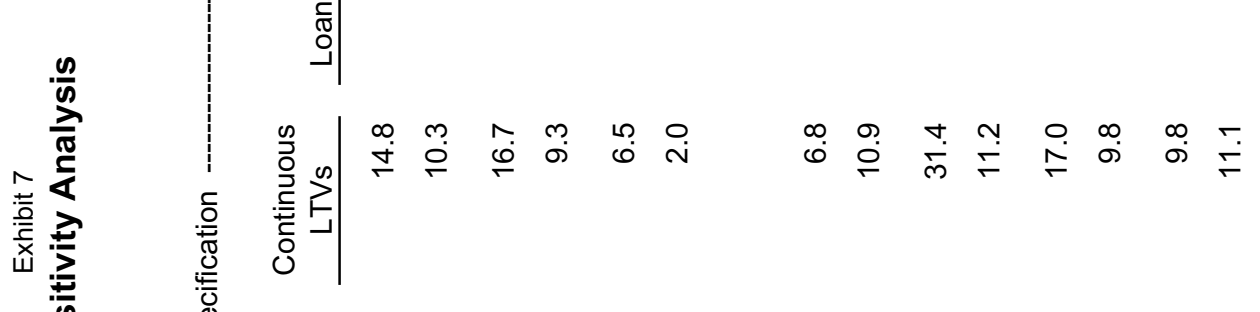

畜

辤

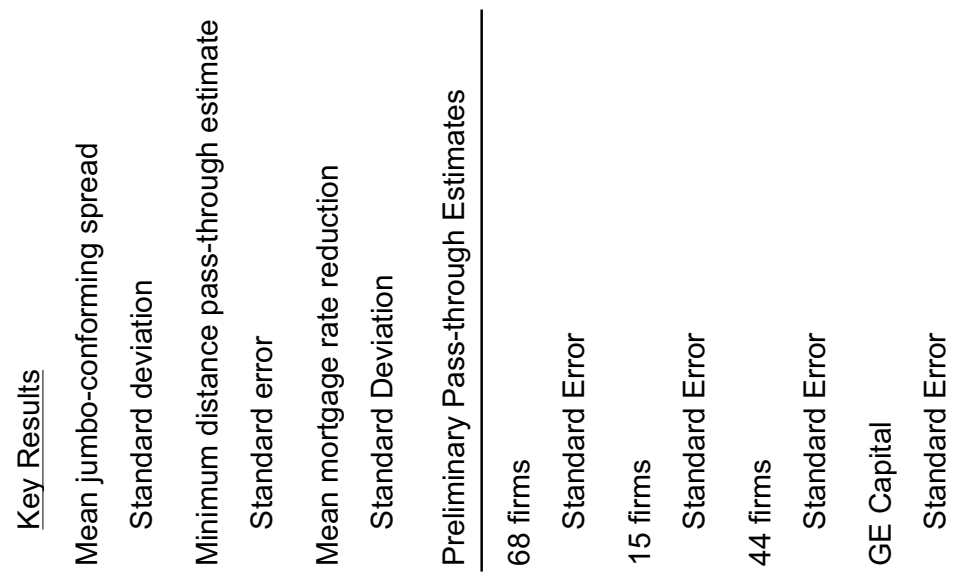




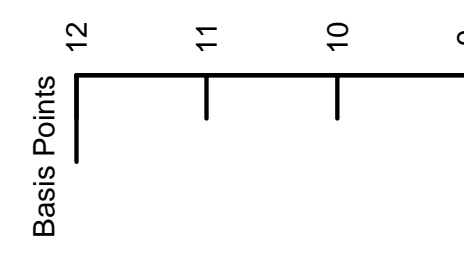

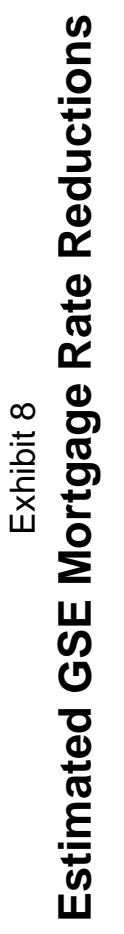

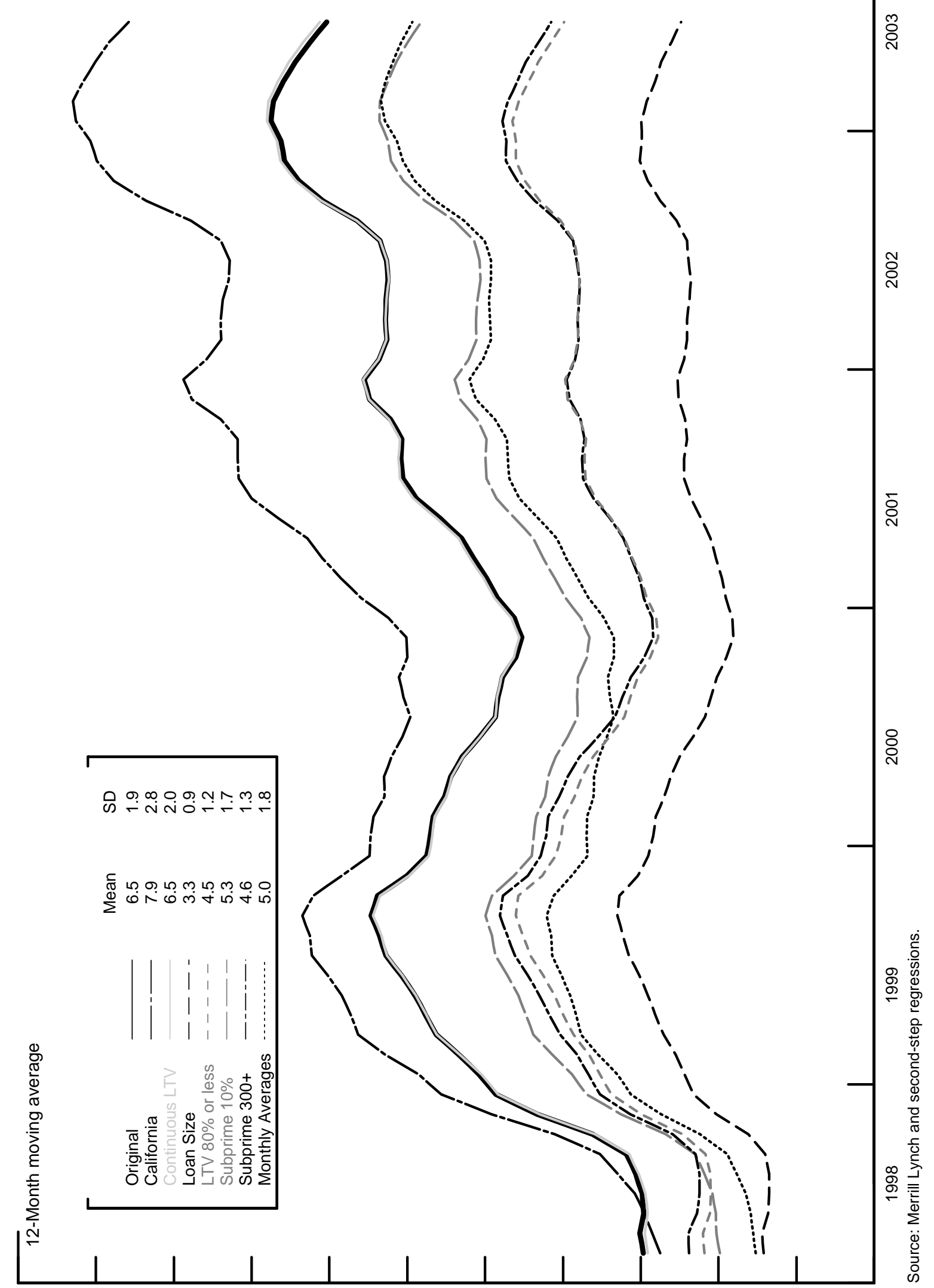


Exhibit 9

\section{Debt Advantage and Swaps}

Spreads to Swaps

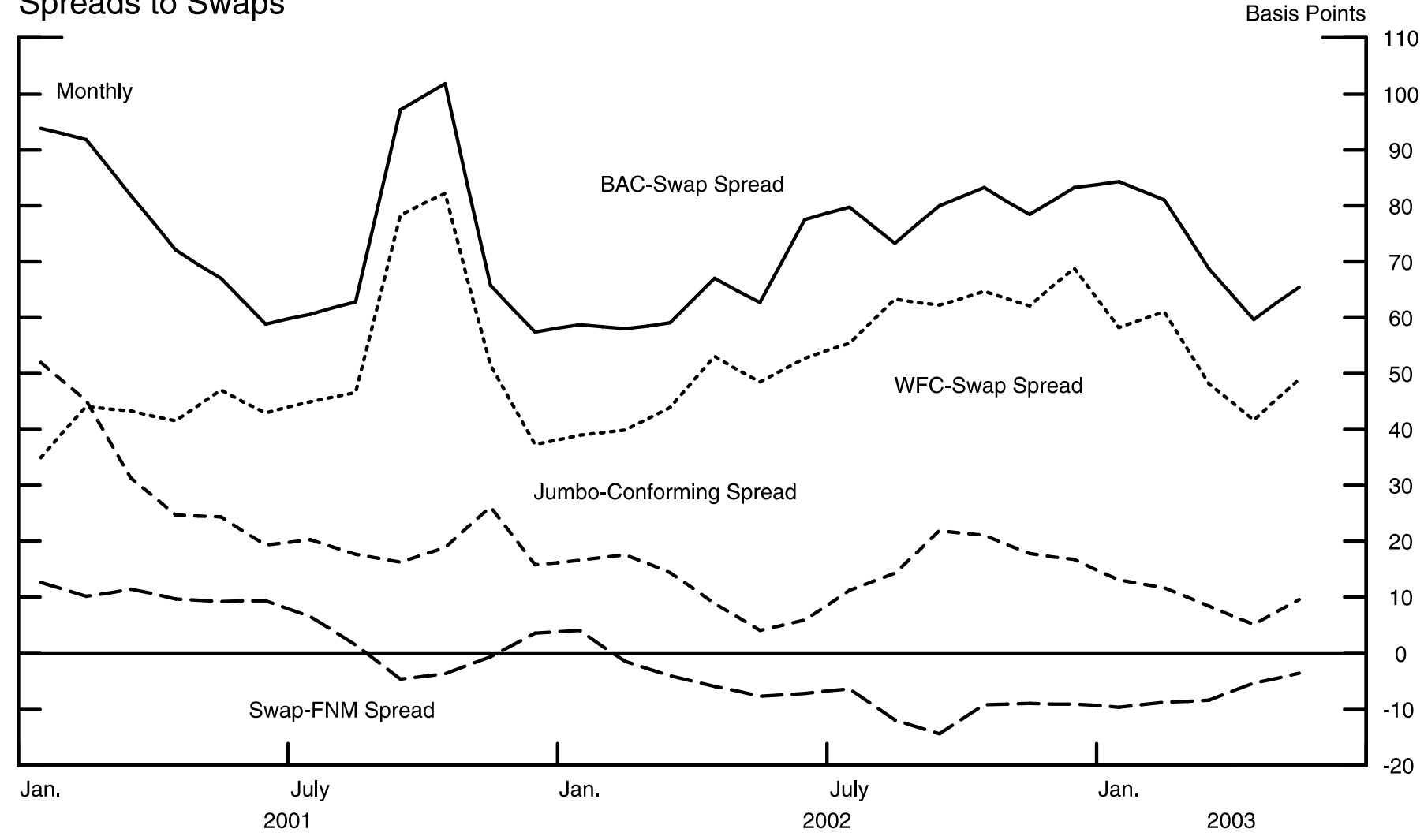

Regression Analysis

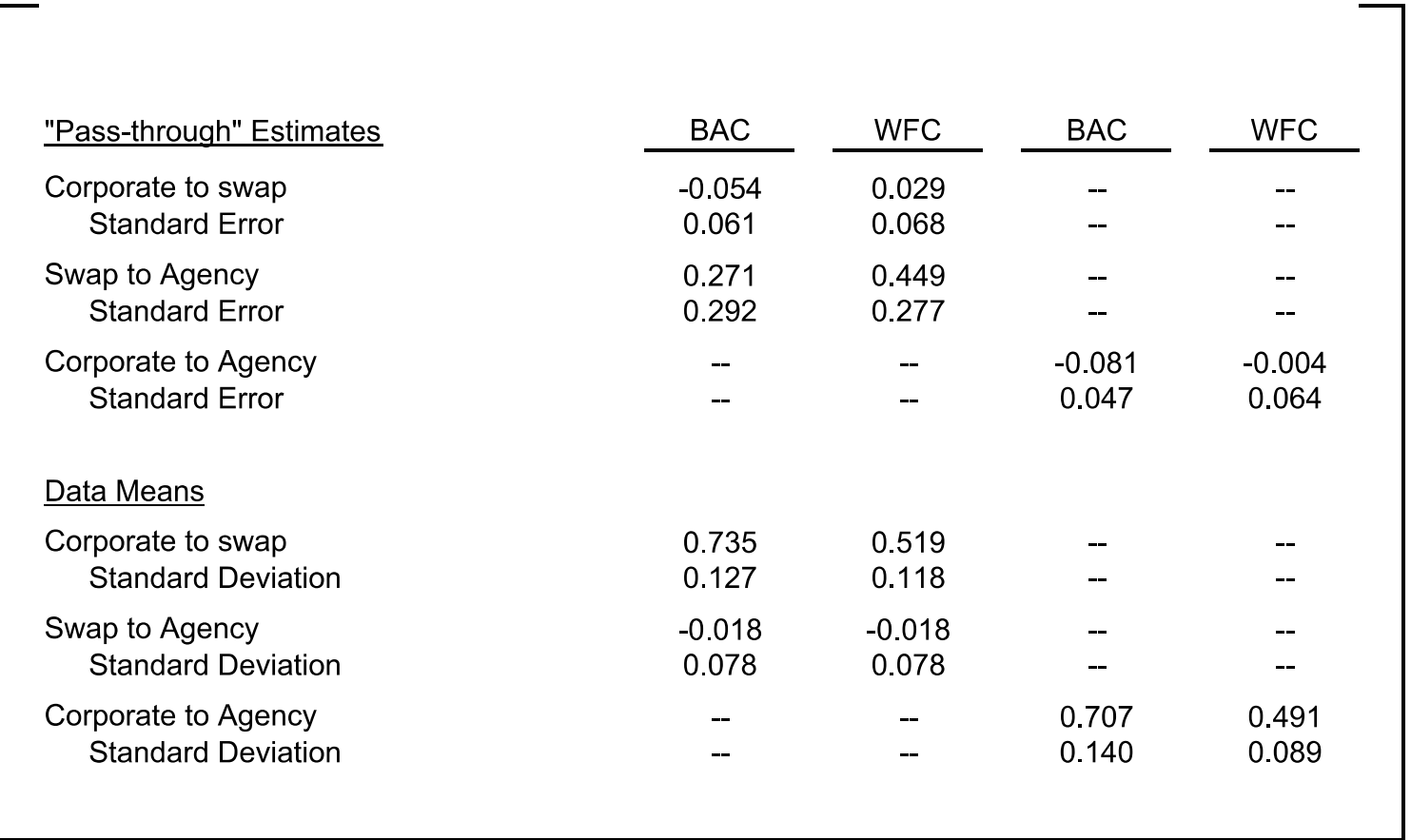

